\title{
Brucellosis in Sheep and Goats and its Serodiagnosis and Epidemiology
}

\author{
Neharika Saxena $^{1 *}$, Balbir Bagicha Singh ${ }^{1}$ and Hari Mohan Saxena ${ }^{2}$ \\ ${ }^{1}$ School of Public Health and Zoonoses, Guru Angad Dev Veterinary and Animal Sciences \\ University, Ludhiana, Punjab, India \\ ${ }^{2}$ Department of Veterinary Microbiology, Guru Angad Dev Veterinary and Animal Sciences \\ University, Ludhiana, Punjab, India \\ *Corresponding author
}

\section{A B S T R A C T}

\begin{tabular}{|l|}
\hline Ke y w o r d s \\
Ovine Brucellosis, \\
Caprine Brucellosis, \\
Serodiagnosis, \\
Seroepidemiology
\end{tabular}

Brucellosis is an important zoonotic disease globally that causes huge economic losses to the livestock owners and is of public health significance. Brucellosis in animals is endemic in India. In sheep and goats, Brucellosis is mainly caused by Brucella melitensis whereas Brucella ovis causes the disease in sheep. The symptoms in infected sheep and goats are abortions, stillbirths and the birth of weak offsprings. Animals that abort may retain the placenta. Sheep and goats usually abort only once, but reinvasion of the uterus and shedding of organisms can occur during subsequent pregnancies. Several studies have been carried out on seroepidemiology of caprine and ovine Brucellosis in India. The tests commonly used for diagnosis of Brucellosis are the milk ring test, Rose Bengal Plate Test (RBPT), Standard Tube Agglutination Test (STAT), Microtiter Plate Agglutination Test (MAT) and ELISA. The RBPT is a rapid screening test for the diagnosis of Brucellosis. The sensitivity of RBPT is very high $(>99 \%)$ but the specificity can be low and it could sometimes give a false positive result. Its positive predictive value is low and a positive test result requires confirmation by a more specific test. Isolation and culture of Brucella organisms is the gold standard test for the diagnosis of Brucellosis.

\section{Brucellosis}

Brucellosis is an important zoonotic disease that causes huge economic losses to the livestock owners and is of great public health significance. It is a chronic infectious disease of livestock, rodents, marine animals and human beings and is caused by facultative intracellular coccobacilli of genus Brucella. It is an important cause of reproductive losses in animals. Abortions, placentitis, epididymitis and orchitis are the most common consequences of the infection. Brucellosis is the second most important zoonotic disease in the world after rabies. The disease in animals is also called as Bang's disease, Enzootic Abortion, Epizootic Abortion, Slinking of Calves, Ram Epididymitis and Contagious Abortion and in humans it is named as Malta fever, Undulant Fever, Mediterranean fever, Rock Fever of Gibraltar, Gastric Fever etc.

Abortion is the most obvious manifestation. Infections may also cause stillborn or weak 
newborn, retained placentas, and reduced milk yield. Usually, general health is not impaired in uncomplicated abortions. Seminal vesicles, ampullae, testicles, and epididymes may be infected in males and organisms are present in the semen. Agglutinins may be demonstrated in seminal plasma. Testicular abscesses may occur (Franco et al., 2007).

Brucellosis is important from public health point of view. Humans are often infected due to direct animal contact or ingestion of contaminated dairy products, causing acute febrile illness - undulant fever - which may progress to a more chronic form and can produce serious complications affecting the musculo-skeletal, cardiovascular and central nervous systems (Mantur et al., 2007). It is a well characterized occupational disease in shepherds, abattoir workers, veterinarians, dairy industry professionals and laboratory personnel (Agasthya et al., 2007).

The predominant symptoms in naturally infected sheep and goats are abortions, stillbirths and the birth of weak offspring. Animals that abort may retain the placenta. Sheep and goats usually abort only once, but reinvasion of the uterus and shedding of organisms can occur during subsequent pregnancies. Some infected animals carry the pregnancy to term, but shed the organism. Milk yield is significantly reduced in animals that abort, as well as in animals whose udder becomes infected after a normal birth. However, clinical signs of mastitis are uncommon. Acute orchitis and epididymitis can occur in males, and may result in infertility. Arthritis is seen occasionally in both sexes. Many non-pregnant sheep and goats remain asymptomatic.

\section{Etiology of brucellosis in small ruminants}

The genus Brucella is currently known to contain nine species classified on the basis of their host specificity; $B$. melitensis affects sheep and goats, and $B$. ovis infects sheep. $B$. melitensis, $B$. suis, and B. abortus are the most virulent and cause human disease in the majority of cases. In sheep and goats, Brucellosis is mainly caused by Brucella melitensis, a Gram-negative coccobacillus or short rod. This organism is a facultative intracellular pathogen. B. melitensis contains three biovars (biovars 1, 2 and 3). All three biovars cause disease in small ruminants, but their geographic distribution varies. Brucella abortus and Brucella suis infections also occur occasionally in small ruminants, but clinical disease seems to be rare. Most breeds of goats are readily infected, but sheep breeds vary greatly in susceptibility. $B$. melitensis infections have also been reported occasionally in cattle, camels and dogs, and rarely in horses and pigs. Infections in sheep and goats can spill over into wild ruminants. However, there is no evidence that these animals serve as reservoir hosts for domesticated sheep and goats. B. melitensis is very contagious to humans.

The main characteristic of organisms of the genus Brucella is their ability to survive within phagocytic and non-phagocytic cells (Celli and Gorvel, 2004).

Three species of Brucella affect humans: $B$. melitensis, B. abortus and B. suis (other species can cause infection in humans, but only rarely). Of these three species, infections by $B$. melitensis are the most common in humans and are also the most serious (Pappas et al., 2005).

The organisms of genus Brucella are facultatively intracellular bacteria that cause disease in a broad range of animal hosts. In vivo they often occur within the cytoplasm of the cells in closely packed clusters (Corbel and Brinley-Morgan, 1984). They are partially acid fast as they are not decolorized by $0.5 \%$ 
acetic acid in the modified Ziehl-Neelsen (MZN) staining (Alton et al., 1988). Flagella, endospore and capsule are absent although capsule like structures have been reported in preparations treated with antiserum. Most of the strains require anaerobic conditions, optimal temperature of $37^{\circ} \mathrm{C}$ and supplemented $\mathrm{CO}_{2}$ for growth. All strains lose viability at $56^{\circ} \mathrm{C}$. Optimal $\mathrm{pH}$ conditions are from 6.6 to 7.4. Brucella strains are fairly resistant to drying and can survive in biological material for long periods, especially at low temperature. They are sensitive to a wide variety of disinfectants including formaldehyde, hypochlorite, iodophors and phenols provided that excess organic matter is not present. The organisms are killed by heat under pasteurization conditions.

Nearly all strains of Brucella are susceptible to gentamicin, tetracycline and rifampicin. Additionally, many strains are also susceptible to ampicillin, chloramphenicol, erythromycin, kanamycin, streptomycin and trimethoprim. Susceptibility to antibiotics can differ among species, biovars and even strains (Vemulapalli, 2000).

\section{Epidemiology of ruminant brucellosis}

Brucellosis is worldwide in distribution and is more common in countries with poor animal and public health programs (Capasso, 2002). Though it has been eradicated from many developed countries like Australia, Canada, Israel, Japan, New Zealand and Europe (Geering et al., 1995), it remains an uncontrolled problem in regions of high endemicity such as Africa, the Mediterranean, Middle East, and parts of Asia and Latin America (Refai, 2002).

Brucellosis is endemic in India and is prevalent in all parts of the country. In a study conducted in various districts of Punjab in 2000, the overall prevalence of Brucellosis was found to be $11.80 \%$ in cattle, $10.67 \%$ in buffaloes and $3.60 \%$ in goats. Analysis of data revealed rise in prevalence of Brucellosis in dairy animals during 1990-99 (Gill et al., 2000). Grewal and Kaur (2000) reported incidence of Brucellosis to be 7\% in sheep and $5 \%$ in goats, respectively in Sangrur district of Punjab, India.

\section{Prevalence of brucellosis in sheep and goats in India}

B. melintensis is the major cause of sheep and goat Brucellosis in many countries including India. The infection is wide spread in India (Kapur and Grewal, 1974). In a national survey of sheep and goat Brucellosis, Isloor $e t$ al., (1998) tested serum samples originating from 10 states, which included 6305 from sheep and 3849 from goats.

The cumulative incidence was $7.9 \%$ in sheep whereas in goats it was $2.2 \%$. This survey indicated widespread prevalence of Brucellosis in small ruminants in the country.

Brucellosis is endemic in India and is prevalent in all parts of the country. Recent serological surveys of small ruminant Brucellosis indicated varying levels of infection in different states - 4.9\% of sheep and $7.6 \%$ of goats in Karnataka (Desai et al., 1995), $11 \%$ sheep and $18 \%$ of goats in northern state of Delhi, 50\% sheep and 16\% goats in Punjab and 33\% sheep and 30\% goats in the western state of Rajasthan (Kumar et al., 1997), 55\% of goats in Andhra Pradesh (Mrunalini et al., 2000) and 24\% of goats and $4.7 \%$ of sheep in Uttar Pradesh (Singh et al., 2000), respectively. It was observed that flocks that had a history of abortion had high incidence of Brucellosis (Mrunalini et al., 2000). The serological evidence of B.ovis infection in 6 out of 102 rams has been reported in the northern state of Himachal Pradesh (Katoch et al., 1996). 
In a study conducted by Avinash Reddy et al., (2014), a total of 252 serum samples were collected from goats of Karnataka and subjected to 5 different serological tests, i.e., Rose Bengal Plate Test (RBPT), Standard Tube Agglutination Test (STAT), 2mercaptoethanol test (2-MET), Indirect ELISA (I-ELISA) and Dot-ELISA to detect the anti-Brucella antibodies. The seroprevalence in goats was $5.15 \%$ by RBPT, $6.34 \%$ by STAT, $1.98 \%$ by 2 -MET, $9.52 \%$ by I-ELISA and $7.14 \%$ by Dot-ELISA. Taking IELISA as reference, the tests revealed the relative sensitivity values in the order: DotELISA $>$ STAT $>$ RBPT $>2$-MET.

In a study conducted in various districts of Punjab in 2000, the overall prevalence of Brucellosis was found to be $11.80 \%$ in cattle, $10.67 \%$ in buffaloes and $3.60 \%$ in goats. Analysis of data revealed rise in prevalence of Brucellosis in dairy animals during 1990-99 (Gill et al., 2000). Grewal and Kaur (2000) reported $7 \%$ incidence of Brucellosis in sheep and $5 \%$ incidence of Brucellosis in goats, respectively in Sangrur district of Punjab, India.

Lone et al., (2013) conducted a study on seroprevalence of Brucellosis in sheep from both organized and unorganized sectors of the Kashmir valley in which sera of 6615 sheep were analyzed and the prevalence of Brucellosis was recorded by RBPT and STAT.

The overall prevalence of Brucellosis recorded in sheep was $6.50 \%$. In this study, the prevalence of Brucellosis was recorded higher in unorganized sector $(14.14 \%)$ as compared to organized sector (3.23\%). In a study conducted in North Gujarat on a total of 1000 serum samples comprising 485 from sheep and 515 from goat, the seroprevalence of Brucellosis in small ruminants was $11.30 \%$, $11.10 \%$, and $8.80 \%$ by RBPT, STAT, and IELISA, respectively (Sadhu et al., 2015).
In yet another study undertaken in North Gujarat and Kutchh regions of Gujarat, a total of 434 serum samples, collected from 14 different locations, were subjected to RBPT, STAT and ELISA. The seropositivity was the highest by i-ELISA (18.20\%), intermediate by RBPT (11.98\%) and lowest by STAT $(9.44 \%)$. In comparison to males, higher seroprevalence was recorded in female sheep. The highest seroprevalence was recorded in Marwari breed followed by Patanwadi and Magara while none was found positive in Chokhla breed. The highest seroprevalence was recorded in Kutchh district followed by Banaskantha, Patan, Sabarkantha and Mehsana districts (Kotadiya et al., 2015).

In a study conducted on Caprine Brucellosis by Priya et al., (2010) in Wayanad district of Kerala, a total of 24 sera were positive by the RBPT with a seroprevalence of $5.7 \%$. Upon STAT testing of all the 420 sera, 18 out of 24 samples $(4.3 \%)$ showed presence of Brucella antibodies. Of the 420 sera examined, 24 $(5.7 \%)$ were seropositive to RBPT, out of which only $18(4.3 \%)$ reacted positively to STAT. The prevalence was higher in female goats $(6.1 \%$ by RBPT and $4.7 \%$ by STAT) than in males $(3.9 \%$ by RBPT and $2.6 \%$ by STAT).

Several serological surveys of small ruminant Brucellosis indicated varying levels of infection in different states. Incidences of $4.9 \%$ in sheep and $7.6 \%$ in goats in Karnataka (Desai et.al., 1995) 11\% sheep and $18 \%$ in goats in Delhi, $50 \%$ sheep and $16 \%$ goats in Punjab and 33\% sheep and 30\% goats in the Rajasthan (Kumar et.al, 1997), 55\% goats in Andhra Pradesh (Mrunalini et al., 2000) and $24 \%$ goats and $4.7 \%$ sheep in Uttar Pradesh (Singh et al., 2000) have been recorded. In a national survey of sheep and goat Brucellosis, Isloor et al., (1998) tested serum samples, which included 6305 from sheep and 3849 from goats originating from 10 states. The 
cumulative incidence was $7.9 \%$ in sheep whereas in goats it was $2.2 \%$. This survey indicated widespread prevalence of brucellosis in small ruminants in the country. The serological evidence of $B$. ovis infection in 6 out of 102 rams has been reported in the state of Himachal Pradesh (Katoch et al., 1996).

In another study (Suryavanshi et al., 2014) a total of 181 and 164 serum samples of sheep and goats were tested for brucellosis by RBPT in which an overall prevalence of $7.32 \%$ and $17.68 \%$ was reported in goats and sheep, respectively.

\section{Ovine and caprine brucellosis}

Caprine and ovine Brucellosis, caused by Brucella melitensis, is an economically important cause of abortion in small ruminants. It is also called as Undulant Fever, Malta Fever, Mediterranean Fever, and Contagious Abortion. This infection causes significant losses from decreased productivity and lost trade in much of the developing world. Most species of Brucella are primarily associated with certain hosts; however, infections can also occur in other species, particularly when they are kept in close contact. Brucella melitensis mainly infects sheep and goats. Most breeds of goats are readily infected, but sheep breeds vary greatly in susceptibility. B. melitensis infections have also been reported occasionally in cattle, camels and dogs, and rarely in horses and pig (Tibary et al., 2006). Infections in sheep and goats can spill over into wild ruminants; however, there is no evidence that these animals serve as reservoir hosts for domesticated sheep and goats.

\section{Brucella melitensis}

B. melitensis is considered to be a re-emerging pathogen in the Middle East (Tibary et al., 2006). It has been eradicated from some nations, but the cost of surveillance to remain B. melitensis - free is significant. B. melitensis is very contagious to humans (Nicoletti, 2013). In humans, Brucellosis is a serious, debilitating and sometimes chronic disease that can affect a variety of organs. Brucella melitensis is a Gram negative coccobacillus or short rod. This organism is a facultative intracellular pathogen. B. melitensis contains three biovars (biovars 1, 2 and 3) (Behroozikhah et al., 2012). All three biovars cause disease in small ruminants, but their geographic distribution varies. Brucella abortus and Brucella suis infections also occur occasionally in small ruminants, but clinical disease seems to be rare. Genetic and immunological evidence suggests that all members of the genus Brucella are closely related, and some microbiologists have proposed that this genus be reclassified into a single species (B. melitensis), which contains many biovars. However, both taxonomic systems are currently in use.

B. melitensis is particularly common in the Mediterranean. It also occurs in the Middle East, Central Asia, around the Persian Gulf (also known as the Arabian Gulf), and in some countries of Central America (Garner et al., 2003). This organism has been reported from Africa and India, but it does not seem to be endemic in Northern Europe, North America (except Mexico), Southeast Asia, Australia, or New Zealand. Biovar 3 is the predominant biovar in the Mediterranean countries and the Middle East, and biovar 1 predominates in Central America. Sporadic cases or incursions are occasionally reported in B. melitensis free countries. In the U.S., cases have mainly been reported in imported goats and rarely in cattle (USDA APHIS CEI, 1999).

\section{Epidemiology of B. melitensis}

Brucella melitensis is the most virulent species of the Brucella genus and has three biovars, 
with biovars 1 and 3 being the ones isolated most frequently in small ruminants in the Mediterranean, the Middle East and Latin America. Brucellosis is a barrier to trade in animals and animal products and causes significant losses from abortion, as well as from being a serious zoonosis. Goats are the classic and natural hosts of B. melitensis and, together with sheep, are its preferred host. In pathological and epidemiological terms, $B$. melitensis infection in small ruminants is similar to B. abortus infection in cattle: the main clinical manifestations of brucellosis in ruminants are abortions and stillbirths, which usually occur in the last third of the pregnancy following infection and usually only once in the animal's lifetime (Blasco and MolinaFlores, 2011).

Healthy animals can be exposed to Brucella infection in many ways, as a large number of bacteria are shed in the birth fluids or fetus, placenta and abortion secretions of infected females. The bacteria have the ability to survive several months outdoors, especially in cold, wet conditions, where they remain infectious to other animals, mainly through ingestion. Brucellae also colonise the udder and contaminate milk (Banai, 2007). Although females calve apparently normally in pregnancies following the first abortion, they continue to shed large numbers of bacteria into the environment. As with $B$. abortus infection in cows, $B$. melitensis can be transmitted congenitally in utero but only a small proportion of lambs and kids are infected in this way and most latent infections of B. melitensis are probably acquired by ingesting colostrum or milk (Grillo et al., 1997).

Despite the low transmission rate, the existence of such latent infections makes it even more difficult to eradicate the disease because, as the bacteria persist without inducing detectable immune response, infected animals are silent carriers of the disease. It is therefore recommended that infected females and their offspring be culled as part of an eradication programme in infected herds (Banai, 2007). The exact mechanism enabling latent Brucella infection to develop is unknown (Blasco and MolinaFlores, 2011). Some female hoggets testing seropositive to Brucellosis have been found to shed B. melitensis in milk postpartum, whereas others do not shed Brucellae despite being infected. While lambs sampled for seven months showed seropositivity, some tested seronegative for Brucellosis in routine tests even though a post-mortem study later revealed them to have been infected with $B$. melitensis. This was also observed in lambs from the same herd that had been born from mothers seronegative for Brucellosis (Godfroid et al., 2011). B. melitensis was successfully isolated from the vaginal discharge of a goat that had aborted but tested seronegative for Brucellosis, making the animal a potential risk for spread undetectable by serological diagnosis (Herrera et al., 2011). While orchitis and epididymitis are uncommon in rams and billy goats, they do occur (Chand et al., 2002). Brucella melitensis can infect not only cattle but also calves, through the ingestion of infected milk (Verger et al., 1989).

The isolation of B. melitensis in dogs has been demonstrated and this has been observed to favour incidence of the disease, as dogs can drag placentas or aborted fetuses to uninfected areas (Hinić et al., 2012). B. melitensis biovars 1 and 3 are the most frequently isolated in Mediterranean countries. In most circumstances, the primary excretion sources are foetal fluids and vaginal discharges after abortion or full-term parturition. Then, excretion of B. melitensis is important in milk and is also common in semen. As it happens in cattle, $B$. melitensis can be transmitted congenitally from ewes to lambs, the animals 
remain infected but seronegative. However, a majority of latent infections are probably acquired through colostrum or milk (Grillo et al., 1997).

\section{Transmission of $B$. melitensis}

In animals, B. melitensis is usually transmitted by contact with the placenta, fetus, fetal fluids and vaginal discharges from infected animals. Small ruminants are infectious after either abortion or full-term parturition. Goats usually shed $B$. melitensis in vaginal discharges for at least 2 to 3 months, but shedding usually ends within three weeks in sheep. This organism can also be found in the milk and semen; shedding in milk and semen can be prolonged or lifelong, particularly in goats. Kids and lambs that nurse from infected dams may shed B. melitensis in the feces.

Most animals become infected by ingestion or through the mucous membranes of the oropharynx, upper respiratory tract and conjunctiva, but Brucella can also be transmitted through broken skin. Although the mammary gland is usually colonized during the course of an infection, it can also be infected by direct contact, with subsequent shedding of the organisms in the milk. In utero infections also occur. Transmission during breeding is possible, but seems to be uncommon during natural mating. $B$. melitensis can be spread on fomites, and could be disseminated mechanically by carnivores that carry away infected material (Moreno et al., 2002).

In conditions of high humidity, low temperatures and no sunlight, Brucella can remain viable for several months in water, aborted fetuses, manure, wool, hay, equipment and clothes. Brucella species can withstand drying, particularly when organic material is present, and can survive in dust and soil. Survival is longer when the temperature is low, particularly when it is below freezing. Cattle and other species can be infected with $B$. melitensis after contact with infected sheep and goats (Tibary et al., 2006). It has not been established whether cattle can maintain this species indefinitely in the absence of contact with small ruminants. Cattle with infected udders can shed B. melitensis in the milk for months or years. Camels also shed this organism in milk. Humans usually become infected by ingesting organisms (including contaminated, unpasteurized dairy products) or by the contamination of mucous membranes and abraded skin (Sauret and Vilissova, 2002). Incubation period i.e., the period between infection and abortion or other reproductive signs is variable.

B. melitensis is highly pathogenic for humans; this organism is considered to be the most severe human pathogen in the genus. Occupational exposure is seen in laboratory workers, farmers, veterinarians and others who contact infected animals or tissues (Yongqun, 2012). Brucellosis is one of the most easily acquired laboratory infections. People who do not work with animals or tissues usually become infected by ingesting unpasteurized dairy products. The Rev-1 $B$. melitensis vaccine is also pathogenic for humans and must be handled with caution to avoid accidental injection or contamination of mucous membranes or abraded skin. Asymptomatic infections can occur in humans. In symptomatic cases, the disease is extremely variable and the clinical signs may appear insidiously or abruptly.

\section{Clinical signs in affected sheep and goats}

The predominant symptoms in naturally infected sheep and goats are abortions, stillbirths and the birth of weak offspring. Animals that abort may retain the placenta. Sheep and goats usually abort only once, but reinvasion of the uterus and shedding of 
organisms can occur during subsequent pregnancies (Ashraf et al., 2015). Some infected animals carry the pregnancy to term, but shed the organism. Milk yield is significantly reduced in animals that abort, as well as in animals whose udder becomes infected after a normal birth. However, clinical signs of mastitis are uncommon. Acute orchitis and epididymitis can occur in males, and may result in infertility. Arthritis is seen occasionally in both sexes (Nicoletti, 2013). Many non-pregnant sheep and goats remain asymptomatic. B. melitensis has also been associated with abortions in cattle, and abortions, orchitis and epididymitis in camels. In dogs, infection with $B$. melitensis is often asymptomatic, and rapid elimination of this organism has been reported. However, abortion, orchitis and epididymitis, and other symptoms of canine Brucellosis can also occur (Dénes and Glávits, 1994).

\section{Morbidity and mortality}

B. melitensis is a significant problem in small ruminants, particularly in developing nations where infections can be widespread. The relative importance of $B$. melitensis for sheep and goats varies with the geographic region, and can be influenced by husbandry practices and the susceptibility of sheep breeds in the region. Management practices and environmental conditions significantly influence the spread of infection. Lambing or kidding in dark, crowded enclosures favors the spread of the organism, while open air parturition in a dry environment results in decreased transmission (Yilma et al., 2016). The abortion rate is high when $B$. melitensis enters a previously unexposed and unvaccinated flock or herd, but much lower in flocks where this disease is enzootic. Ruminants usually abort only during the gestation when they are first infected. Inflammatory changes in infected mammary glands usually reduce milk yield by a minimum of $10 \%$ (Tibary et al., 2006). Fertility in males can be permanently impaired. Deaths are rare except in the fetus.

\section{Post mortem lesions}

At necropsy, granulomatous inflammatory lesions may be present in the reproductive tract, udder, supramammary lymph nodes, other lymphoid tissues, and sometimes in the joints and synovial membranes. Necrotizing orchitis, epididymitis, seminal vesiculitis and prostatitis have been reported. The fetus may be autolyzed, normal or have an excess of blood stained fluid in the body cavities and an enlarged spleen and liver. Placentitis, with edema and / or necrosis of the cotyledons and a thickened and leathery intercotyledonary region can be seen. These lesions are not pathognomonic for Brucellosis (Xavier et al., 2009).

\section{Control of B. melitensis}

B. melitensis is most likely to be introduced into a herd by an infected animal. Semen could also be a source of infection. This organism can be eradicated from a herd by test and slaughter procedures, or by depopulation. In areas where $B$. melitensis is not endemic, infected herds are usually quarantined and the animals are euthanized. Because dogs can be infected, some countries require that shepherd dogs also be euthanized, or treated with antibiotics and castrated, when flocks are depopulated (Sauret and Vilissova, 2002). Any area exposed to infected animals and their discharges should be thoroughly cleaned and disinfected. Infections in other species are generally prevented by controlling $B$. melitensis in sheep and goats.

The B. melitensis Rev1 vaccine is used to control this disease in infected areas. Rev 1 can cause abortions in pregnant animals (Blasco, 1997). This vaccine also interferes 
with serological tests, particularly when it is injected subcutaneously, but conjunctival administration to lambs and kids between the ages of 3 and 6 months minimizes this problem.

Brucella species are readily killed by most commonly available disinfectants including hypochlorite solutions, $70 \%$ ethanol, isopropanol, iodophores, phenolic disinfectants, formaldehyde, glutaraldehyde and xylene; however, organic matter and low temperatures decrease the efficacy of disinfectants. Brucella on contaminated surfaces gets destroyed by disinfectants that include the following components like $2.5 \%$ sodium hypochlorite, 2-3\% caustic soda, $20 \%$ freshly slaked lime suspension, or $2 \%$ formaldehyde solution (all tested for one hour). Ethanol, isopropanol, iodophores, substituted phenols or diluted hypochlorite solutions can be used on contaminated skin. Alkyl quaternary ammonium compounds are not recommended for this purpose (Adel et al., 2015). Autoclaving [moist heat of $121^{\circ} \mathrm{C}$ for at least 15 minutes] can be used to destroy Brucella species on contaminated equipment. These organisms can also be inactivated by dry heat $\left[160-170^{\circ} \mathrm{C}\right.$ for at least 1 hour]. Boiling for 10 minutes is usually effective for liquids. Xylene $(1 \mathrm{ml} /$ liter $)$ and Calcium cyanamide $\left(20 \mathrm{~kg} / \mathrm{m}^{3}\right)$ are reported to decontaminate liquid manure after 2 to 4 weeks. Brucella species can also be inactivated by gamma irradiation (e.g. in colostrum) and pasteurization (Yantorno et al., 1978).

\section{Brucella ovis}

Brucella ovis is an economically important cause of epididymitis, orchitis and impaired fertility in rams. Similar symptoms have been reported in male red deer in New Zealand. $B$. ovis is occasionally associated with abortion in ewes, and can cause increased perinatal mortality in lambs. Ovine epididymitis is caused by Brucella ovis, a Gram-negative coccobacillus or short rod. This organism is a facultative intracellular pathogen. Species affected with $B$. ovis infects sheep, as well as farmed red deer (Odocoileus virginianus) in New Zealand (Nicoletti, 2013). Experimental infections have been reported in goats and cattle, but there is no evidence that these species are infected in nature.

\section{Global distribution and transmission of $B$. ovis}

B. ovis has been reported from Australia, New Zealand, North and South America, South Africa, and many countries in Europe. It probably occurs in most sheep-raising regions of the world (Alton and Forsyth, 1996). B. ovis is often transmitted from ram to ram by passive venereal transmission via ewes. Ewes can carry this organism in the vagina for at least two months and act as mechanical vectors. Some ewes become infected, and shed B. ovis in vaginal discharges and milk. Rams often become persistently infected, and many of these animals shed $B$. ovis intermittently in the semen for 2 to 4 years or longer. B. ovis can also be transmitted by direct non-venereal contact between rams (Cutler et al., 2005).

Ram-to-ram transmission is poorly understood and may occur by a variety of routes, including oral transmission. Shedding has been demonstrated in the urine as well as in semen and genital secretions. Red deer can be infected by venereal transmission, direct contact between infected stags, and experimentally by the intravenous, conjunctival, nasal and rectal routes (Ridler et al., 2002). Similarly to rams, infected stags shed $B$. ovis in semen; however, most stags eliminate the infection within a year and do not seem to transmit the organism long term (Cerri et al., 2002). B. ovis has been found in the urinary bladder and kidneys of infected 
stags. Contamination of pastures does not seem to be an important method of transmission for B. ovis.

\section{Pathogenesis of $B$. ovis}

In experimentally infected rams, clinically detectable lesions become apparent from 3 weeks to 8 weeks after inoculation. B. ovis can cause epididymitis, orchitis and impaired fertility in rams. Initially, only poor quality semen may be seen; sperm motility and concentration may be decreased, and individual sperms are often abnormal. Later, palpable lesions may occur in the epididymis and scrotum. Epididymitis may be unilateral or, occasionally, bilateral. The testes may atrophy. Palpable lesions are often permanent, although they are transient in a few cases. Some rams shed $B$. ovis for long periods without clinically apparent lesions (Poester $e t$ al., 2013). B. ovis can also cause abortions and placentitis in ewes, but this appears to be uncommon. Infected ewes may give birth to weak lambs that die soon after birth. Systemic signs are rare in adult ewes and rams (Xavier et al., 2010).

\section{Morbidity and Mortality}

Approximately $30-50 \%$ of all infected rams have palpable lesions of the epididymis. $B$. ovis has little effect on sperm quality in some individual animals, but causes severe decreases in sperm motility, concentration and morphology in others. Estimates of the abortion rate in ewes and perinatal mortality vary. Some sources report rates of $1 \%$ to $2 \%$, while others suggest that these outcomes are rare. Limited experimental studies have reported abortion rates from $0 \%$ to $8 \%$.

\section{Post mortem lesions}

Lesions are mainly found in the epididymis, tunica vaginalis and testis in rams. The lesions vary from a slight enlargement of the epididymis to large indurations. Epididymal enlargement can be unilateral or bilateral, and the tail is affected more often than the head or body. Spermatoceles containing partially inspissated spermatic fluid may be found in the epididymis. Fibrous atrophy can occur in the testis. The tunica vaginalis is often thickened and fibrous, and can have extensive adhesions. Placentitis may be observed in ewes (Poester et al., 2013).

\section{Control of B. ovis}

B. ovis is generally introduced into a flock by infected animals or semen (Ridler et al., 2002). The prevalence of infection can be reduced by examining rams before the breeding season and culling rams with palpable abnormalities. A commercial killed B. ovis vaccine is used in New Zealand. In other countries, weaner rams may be vaccinated with the $B$. melitensis Rev-1 vaccine (Adosinda et al., 2015).

Vaccination is not practiced in the U.S. Antibiotic treatment has been used successfully in some valuable rams, but it is usually not economically feasible for most animals. Fertility may remain low even if the organism is eliminated. Infections in ewes are generally prevented by controlling infections in rams. B. ovis has been eradicated from sheep flocks in the Falkland Islands, as well as some individual flocks in New Zealand by test and removal methods directed at rams (Lim and Rickman 2004).

\section{Antigenic components of Brucella}

Even though a number of antigenic components of Brucella have been characterized, the antigen that dominates the antibody response is the lipopolysaccharide (LPS). The difference in linkage influences the shape of the LPS epitopes. The specificity 
of the R-LPS is, therefore largely determined by the core polysaccharide. Numerous outer and inner membrane, cytoplasmic and periplasmic protein antigens have also been characterized. Some are recognized by the immune system during infection and are potentially useful in diagnostic tests. Recently, ribosomal proteins have re-emerged as immunologically important components (Corbel, 1976). L7/L12 ribosomal proteins are important in stimulating cell mediated responses (Oliveira and Splitter, 1994). Brucella outer membrane protein was also found to induce lymphocyte proliferation and strong delayed type hypersensitivity reaction in infected cattle (Winter, 1987).

\section{Antigens of diagnostic significance}

Due to the high cost and low individual sensitivity of culture and PCR techniques, the indirect diagnosis of disease is recommended for large-scale surveillance and/or eradication purposes. Detection of antibodies (and at a lesser degree the measure of the cell mediated immunity) against relevant Brucella epitopes is the more practical approach. However, precise antigens and adequate tests have to be used for a proper efficacy and reliability. Particularly relevant is the problem of the specificity of serological tests since antibodies against Brucella epitopes may be present in the animal population due to vaccination and / or of contacts with other Gram-negative bacteria (mainly, Yersinia enterocolitica O:9) sharing cross-reactive epitopes with Brucella.

There is no agreement on what should be the nature and characteristics of a universal antigen for diagnosing Brucellosis. One of the most critical and controversial points concerning serological diagnosis of $B$. melitensis infection in small ruminants is related to which Brucella species and biovars are used in production of antigens. The Rose Bengal Test (RBT) and the complement fixation test (CFT) are the most widely used tests for the serological diagnosis of sheep and goats Brucellosis (Farina, 1985; MacMillan, 1990); they are also the official tests for international trade (European Commission, 2001). The antigenic suspensions (whole cells) used in both tests are made with an Adominant B. abortus biovar 1 (Alton et al., 1988) and, theoretically, infections due to Mdominant strains (i.e. B. melitensis biovar 1) could be misdiagnosed (Alton et al., 1988; MacMillan, 1990). However, existence of a common (C) epitope in the immunodominant S-LPS can account for the high sensitivity of the $B$. abortus biovar 1 antigens to detect $B$. melitensis biovar 1 infections and vice-versa (MacMillan, 1990; Diaz-Aparicio et al., 1993). In fact, no significant differences have been found in the sensitivity of the classical $B$. abortus $1 \mathrm{RBT}$ antigen (AC) between ovine populations infected either with $B$. melitensis biovar 1 (MC) or 3 (AMC) (Blasco et al., 1994a). Moreover, the indirect ELISA (iELISA) sensitivity in sheep, goats and cattle is not affected by the epitopic composition (AC or MC) of the antigens used (AlonsoUrmeneta et al., 1998).

There is limited information on the value of outer membrane (OMP) and inner cytoplasmic proteins for diagnosis of Brucellosis in sheep and goats. The immunoelectrophoretical pattern of cytoplasmic proteins, considered specific for the genus Brucella (Diaz and Bosseray, 1974) shows little differences between the several Brucella species when assayed with polyclonal sera (Diaz et al., 1967; Diaz et al., 1968). The cytoplasmic antigens have been reported to be sensitive and specific enough when used in precipitation tests (Diaz-Aparicio et al., 1994). In contrast, when used in iELISA, there was high background IgG reactivity in sera from Brucella free animals (D'1az-Aparicio et al., 1994; Debbarh et al., 1996a). An important drawback of tests using uncharacterised 
cytosolic proteins is the lack of specificity when testing Rev-1 vaccinated animals, although a partially purified soluble protein of $26 \mathrm{kDa}$ (CP26) from the cytosoluble protein extract (CPE) of $B$. elitensis has been reported as specific when used in an iELISA. However, this test is significantly less sensitive than both RBT and CFT tests to diagnose infected ewes (Debbarh et al., 1996a). A competitive ELISA (cELISA) using CPE extracts and some of the above monoclonal antibodies improved sensitivity in infected sheep, with no antibody responses being detected in Rev-1 vaccinated animals (Debbarh et al., 1996b). Several authors have attempted to identify the main specificities of the antibody response to OMP extracts of $B$. melitensis by using either immunoblotting or cELISAs with specific monoclonal antibodies (Zygmunt et al., 1994a, b; Hemmen et al., 1995; Debbarh et al., 1996b). However, while OMPs of 10, 16, 19, 25-27 and 31-34 kDa were found suitable as potential antigens by immunoblotting or ELISA, the antibody responses detected in infected sheep were scanty and heterogeneous (Zygmunt et al., 1994).

\section{Immune response to Brucella}

Immune response of host to Brucella infection is mediated through both humoral and cell mediated immunity. It is mentioned that immune response mechanisms may diverge and they are dependent on the host and the species or strain of Brucella. Adaptive immunity expands after the activation of innate immunity in order to mount and sustain an antigen-specific response aimed at eradicating bacteria and protecting the host.

Natural or innate resistance mechanisms include the complex of host cell surface receptors for Brucella pathogen associated molecular patterns, factors mediating effective macrophage and dendritic cell maturation and activation, carbohydrate binding proteins, antimicrobial peptides, and inflammatory cytokines orchestrated and regulated by host genome (Adams and Schutta 2010). Brucellae usually enter the body via the oral route and lodge in the mucosa, where the bacteria are ingested by professional phagocytes beneath the sub-mucosa. Once internalized, Brucella is localised in a vacuole that matures from an early to a late endosome and, unless destroyed, goes on to multiply in the endoplasmic reticulum of macrophages. However, not all Brucellae survive: where bacteria are not sufficiently numerous and the animal has a competent immune system, they are directed towards the lysosomes where they are destroyed and the major histocompatibility complex on the cell surface presents the peptides to Th1 and Th2 lymphocytes to elicit an immune response.

The B-lymphocytes govern the humoral arm of adaptive immunity characterized by production of antigen specific antibodies. The role of humoral immunity against intracellular bacterial infections is limited and not protective. Antibody mediated opsonization by immunoglobulins (IgM, IgG1, IgG2a and IgG3) enhances phagocytic uptake of bacteria, limiting the level of initial infection with Brucella, but has little effect on the intracellular course of Brucella infection (Bellaire et al., 2005; Baldwin and Goenka, 2006). From a clinical perspective, detection of antibodies against Brucella LPS is commonly used for the diagnosis of Brucellosis (using seroagglutination tests) in livestock and humans. Absence of B cells is associated with marked antibody independent resistance to Brucella (Al Dahouk, 2003). Brucella antigens induce the production of $\mathrm{T}$ helper type 1 (Th1) cytokines and an adequate Th1 immune response is critical for the clearance of Brucella infection. Skendros and Boura (2013) clearly demonstrated the Th1 nature of adaptive immunity in Brucellosis. Studies on experimental and human 
Brucellosis indicate that interferon- $\gamma$ (IFN $\gamma$ ) is the principal cytokine active against Brucella infection. Mackaness (1964) confirmed cell mediated immunity in Brucellosis suggesting the important role of interaction between $\mathrm{T}$ lymphocytes and macrophages in defense against intracellular pathogens. Brucella has developed sophisticated mechanisms in order to escape from cellular immunity and to achieve the intracellular persistence. Brucella can even cause asymptomatic latent-disease and late reactivation (Ogredici et al., 2010).

Cross-reactions and false positive test results can occur in Brucella antibody tests. The primary immunodeterminant and virulence factor for Brucella species is the cell wall surface lipopolysaccharide, which is antigenically similar to the lipopolysaccharide of other gram-negative rods. False positive Brucella antibody test results can be caused by cross-reactivity of antibodies to Escherichia coli O157, Francisella tularensis, Moraxella phenylpyruvica, Yersinia enterocolitica, and certain Salmonella species (Corbel, 1997). Most cross-reacting antibodies are $\operatorname{IgM}$ (Corbel, 1985), making interpretation of any $\operatorname{IgM}$ assay difficult because of false positivity.

Although the International Office of Epizootics has recommended the RBPT as one of the tests for the diagnosis of bovine brucellosis, some authors (Saravi et al., 1990) have reported unacceptable rate of false negatives with the RBPT. The sensitivity of RBPT is low, so chances of getting a false positive outcome are more when compared to ELISA. False positive results are a major problem which makes serological diagnosis of brucellosis difficult in some cases. Virtually all serological tests for antibody to smooth Brucella species use LPS, part of LPS or whole cells as antigens. The immunodominant epitope on the surface of the smooth cell is OPS the outer most portion of LPS. Most, but not all, of the problems arise from an immune response of the animal to other microorganisms which share epitopes with Brucella species OPS. False negative reactions occur in acidified antigens, especially in RBPT. The classes of antibodies involved in the two tests RBPT and ELISA are different. Even differences in sensitivities of C-ELISA and I-ELISA have been reported (Mythili et al., 2011). Furthermore, the prevalence rate of the disease would vary among various reports because variations occur in different populations on account of differences in breeds, animal husbandry and management practices and preventive and control measures adopted.

\section{Common serodiagnostic tests for brucellosis}

The most incontrovertible diagnosis of Brucellosis is made by bacteriological isolation which has draw-backs like low sensitivity, time consuming and cumbersome. At times, isolation is not possible even from known positive cases (Seleem et al., 2010) because of many factors like slow growth and poor sensitivity. The low sensitivity for isolation is attributed to many factors like the individual laboratory practices, quantity of pathogen in clinical samples, stage of infection, use of antibiotics before diagnoses and the methods used for culturing and the cultured strain (B. melitensis is more readily cultured from clinical sample than B. abortus). As a result, recourse is taken in serological tests. A large number of serological tests are available for diagnosis of Brucellosis of which RBPT, STAT and CFT have been used extensively to diagnose Brucellosis in animals.

The conventional serological tests for diagnosis of Brucellosis have their limitations. It has been shown that culture positive animals were negative in STAT, RBPT and CFT (Sutherland et al., 1986). On the other hand, culture positive animals negative by RBPT and CFT have been found positive by I- 
ELISA (Araj, 1989). I-ELISA has been reported to be highly sensitive and specific and it can be used for the determination of specific IgG, IgM and IgA Brucella antibodies in blood, serum and CSF (Nielsen et al., 1996). Further, I-ELISA has been considered as gold standard test by many workers to compare the results of other tests in case of Brucellosis (Isloor et al., 1998). The speed and ease with which the I-ELISA can be performed, the high sensitivity and specificity values and the use of an easily obtainable antigen make the indirect I-ELISA an excellent test for the diagnosis of Brucellosis. STAT measures the total amount of agglutinating antibodies ( $\operatorname{IgM}$ and $\mathrm{IgG}$ ). IgG antibodies are considered better indicators of an active infection than IgM.

\section{Serodiagnosis of brucellosis in sheep and} goats

It is widely assumed that serological tests used for $B$. abortus infection in cattle are also adequate for diagnosis of $B$. melitensis infection in small ruminants. Accordingly, RBT and CFT are the most widely used tests for the serological diagnosis of Brucellosis in ruminants (Farina, 1985; Alton, 1990a; MacMillan, 1990). Although the Rev-1 vaccine is an essential tool to control small ruminants Brucellosis, when applied under standard conditions (i.e. full dose via the subcutaneous route), it induces long lasting serological responses that interfere with subsequent serological screening (Alton, 1990a; MacMillan, 1990). This problem impedes combined use of vaccination and test and slaughter programmes for eradicating Brucellosis.

\section{Rose Bengal Plate Test (RBPT)}

The Rose Bengal Plate Test (RBPT) (Fig. 1) is often used as a rapid screening test (RuizMesa et al., 2005) and considered as a reliable test in the diagnosis of brucellosis (Oomen and Waghela, 1974). The sensitivity of RBPT is reported to be very high $(>99 \%)$ but the specificity can be disappointingly low (Barroso et al., 2002). As a result, the positive predictive value of the test is low and a positive test result thus requires confirmation by a more specific test (Smits and Kadri, 2005). Gram negative bacteria such as Yersinia enterocolitica, Vibrio cholera, Campylobacter fetus, Bordetella bronchiseptica and Salmonella spp. may cross react with smooth Brucella spp. (Corbel and Brinley-Morgan, 1984).

Despite the scanty and sometimes conflicting available information (Fensterbank and Maquere, 1978; Farina, 1985; Alton, 1990b; MacMillan, 1990; Blasco et al., 1994a, b), this test is internationally acknowledged as the test of choice for the screening of Brucellosis in small ruminants (Garin-Bastuji and Blasco, 2004).

However, standardization conditions suitable for diagnosing cattle infection (MacMillan, 1990; European Commission, 2001; GarinBastuji and Blasco, 2004) are not adequate in sheep and goats (Blasco et al., 1994a, b) and account for the low sensitivity of RBT antigens in small ruminants (Blasco et al., 1994a; Falade, 1978); along with the fact that a high proportion of animals in infected areas give results negative in RBT, but positive in CFT, question the efficacy of the present RBT as an individual test (Blasco et al., 1994a).

\section{Standard tube agglutination test}

The Standard tube agglutination test (STAT) (Fig. 2) detects antibodies to the S-LPS. Antibodies reacting against S-LPS can also be detected by other tests, such as ELISA (enzyme-linked immunosorbent assay) and the Coombs test. 


\section{Brucella microagglutination test}

CDC utilizes a test called the Brucella microagglutination test (BMAT) (Fig. 3), a modified version of the serum (tube) agglutination test (SAT), that can detect antibodies to Brucella species abortus, melitensis or suis.

\section{Enzyme linked immunosorbent assays (ELISA)}

Good diagnostic results have been obtained in sheep and goats with iELISA or, at a lesser degree, cELISA using various antigens, but generally those with a high content of smooth lipopolysaccharide (LPS) are the most reliable (Fig. 4). These ELISA provide similar or better sensitivity than both RBT and CFT, but like classical tests, ELISA are unable to differentiate infected animals from animals recently vaccinated with the Rev-1 vaccine (Jimenez' de Bagu“es' et al., 1992; Blasco et al., 1994b; D'1az-Aparicio et al., 1994; Delgado et al., 1995; Ficapal et al., 1995; Ferreira et al., 2003) or animals infected with cross-reacting bacteria. However, the association of the conjunctival vaccination procedure and the presence of a moderate interval after vaccination minimize or abrogate the specificity problems. A similar indirect technique has been also proposed for diagnosing sheep Brucellosis in individual or pooled milk samples (Alonso-Urmeneta et al., 1998), but the test lacks sensitivity when compared with serological tests.

A highly immunogenic periplasmic protein from B. abortus (Rossetti et al., 1996) or B. melitensis (Cloeckaert et al., 1996a) has been applied to Brucellosis diagnosis in different host species. Indirect and competitive ELISA with this antigen could be sensitive and specific tests for diagnosing $B$. melitensis infection in sheep and have been reported to be useful in differentiating Rev-1 vaccinated from infected animals (Debbarh et al., 1995, 1996b; Cloeckaert et al., 1996b). All these ELISA have potential advantages in sensitivity and specificity with respect to both RBT and CFT, but their diagnostic efficacy at large scale is unknown and a great deal of standardisation work is still required (GarinBastuji and Blasco, 2004).

Fig.1 RBPT testing of sera from animals suspected of Brucellosis

Left: Brucellosis positive serum; Right: Brucellosis negative serum 
Fig.2 Standard Tube Agglutination Test

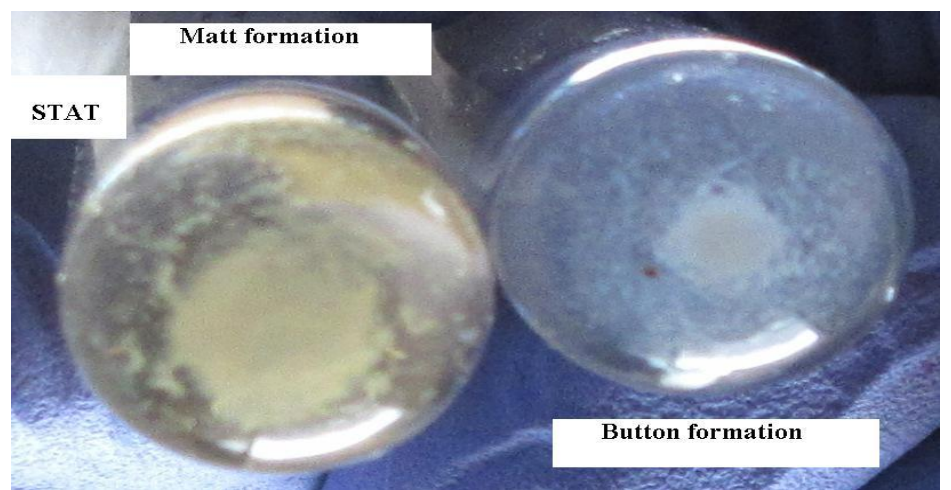

Left: Tube with matt formation (positive); Right: button formation (negative)

Fig.3 Microtiter agglutination test showing negative (button) and positive (matt) wells

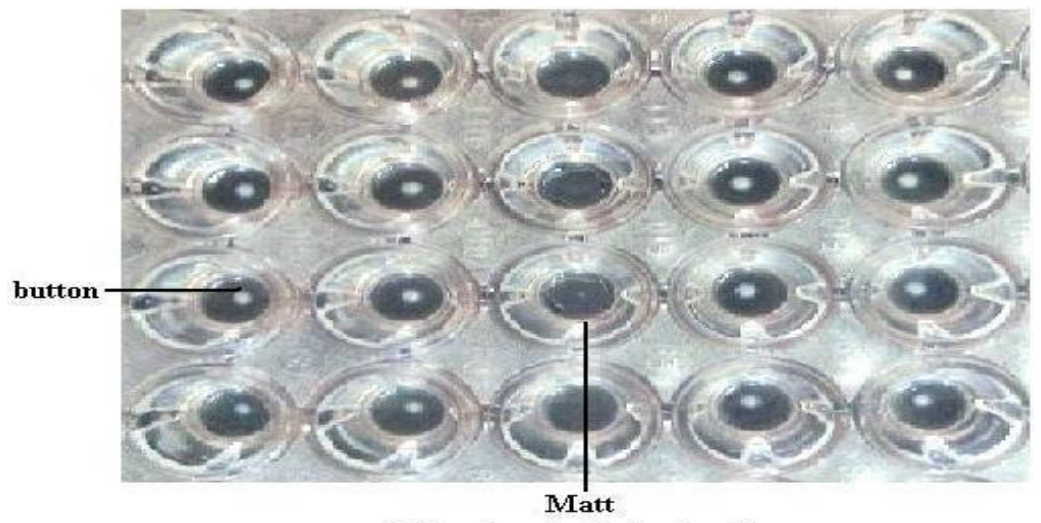

Microtiter Agglutination Test

Fig.4 ELISA plate showing positive (colorless) and negative (yellow) wells

ELISA plate showing positive and negative serum samples of Sheep and Goat.

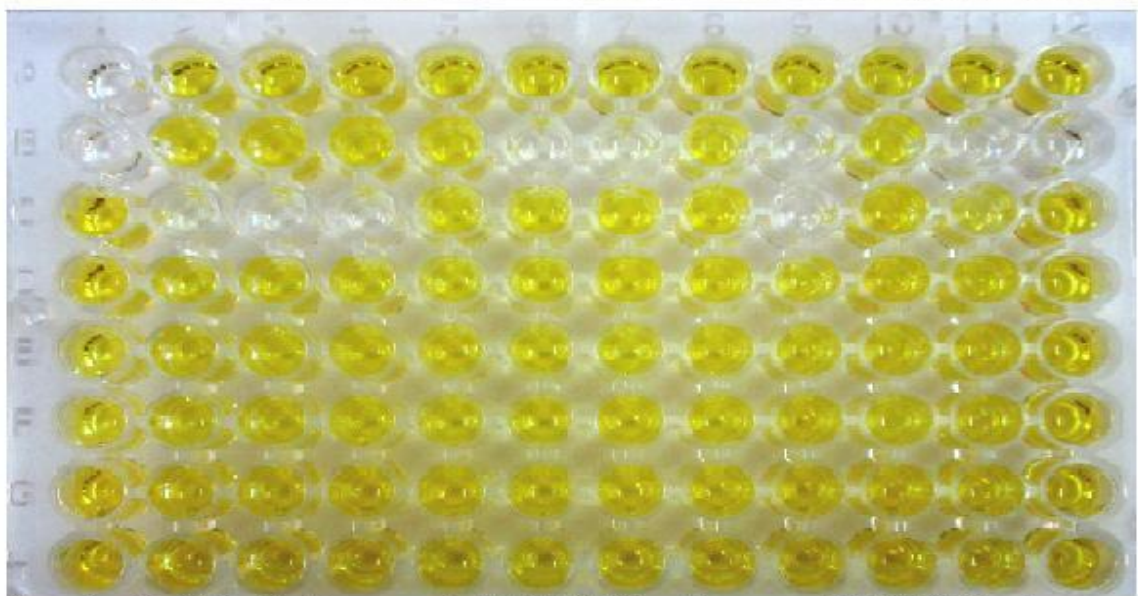

Controls-Al \& Bl: Positive control, C1 \& D1:Negative control, E1 \& F1:Weak

Positive control, Gl \& Hl: Conjugate control

Positive samples-C2,C3,C4,C9,B6,B7,B9,B11,B12

Negative samples -Rest all are negative. 


\section{Sensitivity and specificity of various diagnostic tests}

Different diagnostic tests have been validated for diagnosing Brucellosis in small ruminants, but only the Rose Bengal test (RBT) and the complement fixation test (CFT) are approved for diagnosis of small ruminant Brucellosis in the European Union (EU) legislation on intraCommunity trade (Council Directive 91/68/EEC). However, there is evidence that both tests are less sensitive and specific for the diagnosis of Brucellosis in sheep and goats than in cattle (Blasco et al., 1994b; Garin-Bastuji et al., 1998).

According to Biancifiori et al., (2000), the cELISA has a diagnostic sensitivity $(99.4 \%)$ and specificity $(98.9 \%)$ in sheep and goats comparable to that of many standard indirect ELISA methods. In addition, the test proved able to distinguish between vaccinated and infected animals with an accuracy of up to $90 \%$ and result reproducibility of $93 \%$. They concluded that cELISA could be useful for differentiation of Rev.1 vaccinated and naturally infected sheep and goats.

The serological tests used in previous studies were the Rose Bengal Test (RBT), Standard Tube Agglutination Test, ELISA or Plate Agglutination Test. None of the aforementioned tests are perfect. So, the prevalence reported using these tests are not true prevalence due to misclassification of some of the tested animals. Moreover, the performance of these tests has not been validated in naturally infected small ruminants. Tests are normally validated by comparing with the gold standard or perfect test. However, the gold standard for the diagnosis of Brucellosis is isolation and identification of the organism (Alton et al., 1988; OIE, 2008). The TAT has a high sensitivity in respect of $\operatorname{IgM}$ rather than $\operatorname{IgG}$ as reported by Alton (1977). On the other hand, MacMillan (1990) reported that TAT failed to show significant titres in recent and chronic Brucella infection. While Corbel (1972) reported that TAT gives false positive reaction as a results of cross reaction between the antigen of Brucella and other organisms or due to the presence of non-specific agglutinins in bovine sera. The presence of some samples collected from non-reactors (Brucella free cows) reacted positively with RBPT, BAPT and TAT. This may be attributed to the presence of some bacteria as Escherichia coli, Salmonella Dublin, Yesinia enterocolitica 0:9 and Pasteurella tularensis in the body fluids and secretions which react positively with the tests used in diagnosis of Brucellosis causing faults or error in the interpretation of the results.

The FPA has been reported to be the test with the smallest sensitivity and iELISA that with the smallest specificity. iELISA was found to be the most sensitive test, whilst cELISA the most specific. The cELISA had the best and FPA the second best positive predictive value. cELISA had the best negative predictive value, which is expected due to the use of monoclonal antibodies. This test may be ultimately used for confirming negative samples, as it is not influenced by nonspecific reactions (Nielsen et al., 1996). iELISA would be valuable for use at the early stage of a control program, whilst cELISA at its final stage. Although the FPA did not appear to be as accurate, when compared to the other two methods when testing vaccinated animals, it was the easier, cheaper (use of reagents is minimal) and quicker to perform; further investigation should be carried to establish its value in large scale surveys, where a great number of samples need to be tested. Furthermore, Nielsen and Gall (2001) have reported its use in testing stored whole blood samples with an almost $100 \%$ sensitivity and specificity; this can be an added advantage. The test may also be 
used in samples from all animal species, as well as in poor quality samples.

\section{Cell-mediated immunity (CMI) based diagnosis}

An alternative diagnostic test is the brucellin skin test, which can be used for screening unvaccinated flocks, provided that a purified (S-LPS free) and standardized antigen preparation is used (Bhonghibhat et al., 1970; Jones et al., 1973; Jones and Marly, 1975; Fensterbank, 1985; Blasco et al., 1994a, b). SLPS (Blasco et al., 1994a, b) does not take part in DTH reactions (Jones et al., 1973; Jones, 1974) and may provoke antibodymediated inflammatory reactions or induce antibodies that interfere with subsequent serological screening. One such commercially available preparation is brucellin INRA, prepared from a rough strain of $B$. melitensis (Blasco et al., 1994 a, b). The brucellin skin test has a high sensitivity and, in the absence of vaccination, is considered one of the most specific diagnostic tests (Alton et al., 1988). This test is of particular value for the interpretation of FPSR due to infection with cross-reacting bacteria (FPSR animals are negative in the skin test), especially in Brucellosis-free areas. Despite its high sensitivity, not all infected animals show positive skin test responses and, moreover, Rev-1 vaccinated animals can react in this test for years (Fensterbank et al., 1982; GarinBastuji et al., 1998; Pardon et al., 1989). Therefore, this test cannot be recommended either as the sole diagnostic test or for the purposes of international trade. The site and route of allergen inoculation are not important factors affecting its sensitivity (Fensterbank, 1985; Alton, 1990; Blasco et al., 1994a, b).

The method considered more efficient and practical for sheep and goats is the subcutaneous inoculation in the lower eyelid with reading $48 \mathrm{~h}$ after inoculation (Jones et al., 1973; Jones and Marly, 1975; Fensterbank et al., 1985). However, since mixed DTHantibody mediated intradermal reactions are occasionally observed, a reading time of $72 \mathrm{~h}$ seems advisable for a better assessment of true DTH reactions (Blasco et al., 1994a, b). Anergy induced by repeated skin testing, well known in bovine tuberculosis (Radunz and Lepper, 1985), is not absolute in Brucellosis, but the responses lessen within the 24 days that follow a positive skin test (Blasco et al., 1994a, b). No information has been published on the diagnostic value of in vitro CMI tests (e.g. IFN detection) for Brucellosis of small ruminants.

\section{Diagnosis of $\boldsymbol{B}$. melitensis infection in sheep and goats}

Clinical Brucellosis should be considered in flocks and herds when abortions and stillbirths occur without concurrent illness. For differential diagnosis, other diseases causing abortion in small ruminants, particularly chlamydiosis and coxiellosis, should be considered. B. ovis can also cause epididymitis and orchitis in rams. Microscopic examination of smears stained with the Stamp's modification of the ZiehlNeelsen method can be useful for a presumptive diagnosis, particularly if the direct examination is supported by serology (CDC, 2005). Other organisms that cause abortions such as Chlamydophila abortus and Coxiella burnetii can resemble Brucella ovis, which causes epididymitis and orchitis in rams, can also be confused with $B$. melitensis (Nicoletti, 1989; Garner et al., 2003).

The clinical diagnosis is complicated by variable incubation period and absence of apparent clinical signs, except abortion. While isolation and culture of Brucella organisms is regarded as the gold standard test for laboratory diagnosis of Brucellosis, its sensitivity is low because the Brucellae are 
fastidious micro-organisms that can easily be overgrown by other contaminating bacteria. More importantly, the procedure is associated with high risk of infection to laboratory personnel (Alton et al., 1988). Therefore, serological tests are often relied upon for the diagnosis of Brucellosis.

The tests commonly used for diagnosis of Brucellosis are the milk ring test (MRT), serum agglutination test (SAT), Rose Bengal Plate Test (RBPT), anti-globulin (Coombs') test, 2 - mercaptoethanol test, rivanol, and the enzyme- linked immunosorbent assay (ELISA) (Morgan, 1982). The RBPT is a very sensitive test. However, it could sometimes give a false positive result because of S19 vaccination or of false positive serological reactions (OIE, 2009a). Also, Gram negative bacteria such as Yersinia enterocolitica, Vibrio cholera, Campylobacter fetus, Bordetella bronchiseptica and Salmonella spp. may cross react with smooth Brucella spp. (Corbel and Brinley-Morgan, 1984).

Immunostaining is sometimes used to identify Brucella in smears. Serology can be used for a presumptive diagnosis of brucellosis, or to screen flocks. The most commonly used serological tests in small ruminants are the buffered Brucella antigen tests (the card and Rose Bengal plate agglutination tests) and the complement fixation test. Indirect or competitive enzyme-linked immunosorbent assays (ELISAs) are also used. In vaccinated sheep and goats, the native hapten-based gel precipitation tests (gel diffusion or radial immuno-diffusion tests) are sometimes used to distinguish vaccination from infection (Kahn and Line, 2003). Other serological tests are in development or in use in research and other special situations. A brucellin allergic skin test is sometimes used to test unvaccinated sheep and goats for $B$. melitensis. This test is performed by injecting the allergen into the lower eyelid (Garner et al., 2003). A definitive diagnosis can be made if $B$. melitensis is cultured from an animal.

The vaccine strain (B. melitensis strain Rev.1) can be distinguished from field strains by its growth characteristics and sensitivity to antibiotics and other additives. Animal inoculation is uncommonly used for isolation, but occasionally necessary when other techniques fail. Guinea pigs or mice can be used for this purpose. Polymerase chain reaction (PCR) techniques, PCR restriction fragment length polymorphism and Southern blotting are available in some laboratories (CDC, 2005).

Milk samples and vaginal swabs are particularly useful for diagnosis in live sheep and goats. B. melitensis can also be cultured from aborted fetuses (stomach contents, spleen and lung) or the placenta (Alton et al., 1988). The spleen, mammary and genital lymph nodes, udder and late pregnant or early postparturient uterus are the most reliable samples to collect at necropsy. This organism can also be cultured from semen, the testis or epididymis, and arthritis or hygroma fluids.

\section{Diagnosis of ovine Brucellosis}

B. ovis infections should be considered when rams develop epididymitis and testicular atrophy, or poor semen quality is seen (Ridler et al., 2002). Some but not all rams have palpable lesions. For differential diagnosis, other bacteria that cause epididymitis and orchitis should be considered. Commonly isolated organisms include Actinobacillus seminis, A. actinomycetemcomitans, Histophilus ovis, Haemophilus spp., Corynebacterium pseudotuberculosis ovis, Chlamydophila abortus and B. melitensis, but many other organisms can also cause these conditions. Sterile, trauma-induced spermatic granulomas should also be ruled out (Webb et al., 1980). 
Laboratory tests like microscopic examination of semen or smears stained with the Stamp's modification of the Ziehl-Neelsen method can be useful for a presumptive diagnosis. Other organisms such as Chlamydophila abortus and Coxiella burnetii can resemble. A definitive diagnosis can be made if $B$. ovis is cultured from an animal. Brucella spp. can be isolated on a variety of plain media, or selective media such as Farrell's medium or Thayer-Martin's modified medium. Enrichment techniques can also be used. $B$. ovis colonies usually become visible after three to four days (Nicoletti, 2013). The colonies are round, shiny and convex, and approximately $0.5-2.5 \mathrm{~mm}$ in diameter. $B$. ovis is a rough (R) form of Brucella; this can be observed by examining the colony by oblique illumination (OIE, 2004).

B. ovis can often be identified to the species level by its cultural, biochemical and serological characteristics, although phage typing can be used for definitive identification. Pulse-field gel electrophoresis or specific polymerase chain reaction restriction fragment length polymorphism (PCR RFLP) can also distinguish B. ovis from other Brucella species. Serological tests used to detect $B$. ovis include enzyme-linked immunosorbent assay (ELISA), agar gel immunodiffusion (AGID) and complement fixation (Webb et al., 1980). Other tests including hemagglutination inhibition and indirect agglutination have also been described, but are less commonly used. Dichelobacter nodosus, which causes foot rot, is reported to cross-react with $B$. ovis in serological assays, but the practical significance is unknown. B. ovis can also be detected by PCR.

The most reliable and the only unequivocal method for diagnosing animal Brucellosis is isolation of Brucella spp. (Alton et al., 1988). The bacteriological diagnosis of $B$. melitensis can be made by means of the microscopic examination of stained smears from vaginal swabs, placentas or aborted foetuses (Stamp's method). However, morphologically related organisms such as Brucella ovis, Chlamydophila abortus or Coxiella burnetii can cause misleading diagnoses. Therefore, isolation of B.melitensis on appropriate culture media is recommended for accurate diagnosis.

Vaginal excretion of $B$. melitensis is usually copious and persists several weeks after abortion (Alton, 1990a). Thus, taking vaginal swabs and milk samples is the best way to isolate $B$. melitensis from sheep and goats. $B$. melitensis does not require serum or $\mathrm{CO}_{2}$ for growth and can be isolated on ordinary solid media under aerobic conditions at $37^{\circ} \mathrm{C}$. Nevertheless, due to the overgrowing contaminants usually present in field samples, selective media are needed for isolation purposes. The Farrell selective medium, developed for isolation of B. abortus (Farrell, 1974), is also recommended for B. melitensis (Alton et al., 1988).

PCR assay has been shown to be a valuable method for detecting DNA from different microorganisms and provides a promising option for diagnosis of Brucellosis. Several authors reported good sensitivity of PCR, based on different molecular markers (16S rRNA, bscp31, IS 6501/711) (Romero and Lopez-Goni, 1999) for detecting of Brucella DNA with pure cultures (Farrell, 1974). However, few studies have been performed with clinical or field samples and even fewer have evaluated the PCR as a diagnostic tool (Fekete et al., 1992). The possibility of using the PCR technique to detect the DNA of dead bacteria or in paucibacillary samples and even in samples highly contaminated with other microorganisms, could increase the rate of detecting infected animals. However, up to now, no technique appears sensitive enough 
to replace classical bacteriology on all kinds of biological samples. Several methods, mainly PCR-RFLP and Southern-blot analysis have been employed to find DNA polymorphism to differentiate some Brucella species and biovars. Specific molecular markers have been developed for distinguishing the Rev-1 strain from $B$. melitensis wild strains (Cloeckaert et al., 2002). Recently, a new method has been described for fingerprinting Brucella isolates based on multi-locus characterization of a variable number, 8-base pair, tandem repeat. The technique is highly discriminatory among Brucella species or strains (Bricker et al., 2003).

\section{Biomarkers of Brucella and brucellosis}

In the absence of a single accurate serodiagnostic test for Brucellosis based on antibody detection, efforts are on for identifying a specific biomarker of Brucellosis for correct diagnosis. The biomarker is a characteristic that is objectively measured and evaluated as an indicator of normal biological processes, pathogenic processes, or pharmacologic responses to a therapeutic intervention or other health care intervention. The biomarker is either produced by the diseased organ or by the body in response to disease. Biomarkers are potentially useful along the whole spectrum of the disease process. Before diagnosis, markers could be used for screening and risk assessment. During diagnosis, markers can determine staging, grading, and selection of initial therapy. Genetics, genomics, proteomics and modern imaging techniques and other high-throughput technologies allow us to measure markers. However, there are few studies on biomarkers in the diagnosis of Brucellosis.

Diagnosis of Brucellosis is currently performed with serological techniques that mainly detect antibodies against lipopolysaccharide. However, antibodies against lipopolysaccharide are also induced in animals vaccinated with Brucella sp. attenuated strains. Therefore, an important goal in Brucellosis research is the identification of protein antigens that induce an intense antibody response during infection and that are not essential for the induced protective immunity or for survival of the bacterium. Vaccination with a mutant of the vaccine strain lacking the gene coding for a protein of interest, in association with a serological test based on the purified protein, should allow the differentiation between vaccinated and infected animals. The most encouraging results until present have been obtained with the Brucella sp. BP26 protein, which has been simultaneously identified by three nonrelated research groups as an immunodominant antigen in infected cattle, sheep, goats, and humans (Cloeckaert et al., 1996; Rossetti et al., 1996). Accordingly, the region of BP26 between amino acids 55 and 152 might provide better specificity results than the entire recombinant BP26, avoiding false-positive reactions with sera from Brucella-free sheep, for the serological diagnosis by indirect ELISA of sheep Brucellosis caused by B. melitensis or B. ovis. This region of BP26 might be either obtained as a synthetic peptide or purified from recombinant $E$. coli/pCP28124 as fusion protein with LacZ.

Goldbaum et al., (1993) obtained some anticytoplasmic protein monoclonal antibodies (MAbs) from mice immunized by infection with Brucella ovis cells. One of these MAbs, BI24, was used to purify by immunoaffinity a protein with a pI of 5.6 and a molecular mass of $18 \mathrm{kDa}$. This protein was present in all of the rough and smooth Brucella species studied, but it could not be detected in Yersinia enterocolitica 09. Three internal peptides of this protein were partially 
sequenced; no homology with other bacterial proteins was found. The immunogenicity of the $18-\mathrm{kDa}$ protein was studied with both human and bovine sera by a capture enzymelinked immunosorbent assay system with MAb BI24.

In another study by Manat et al., (2016) a purified recombinant outer membrane protein 28 (rOMP28) of Brucella species produced in Escherichia coli (E. coli) was evaluated as a diagnostic antigen in an Indirect ELISA (IELISA) for bovine Brucellosis. The results showed that the rOMP28 of Brucella spp. could be a good candidate for improving serological diagnostic methods for bovine Brucellosis.

A Brucella protein named CP28, BP26, or Omp28 has been identified as an immunodominant antigen in infected cattle, sheep, goats, and humans. In sheep experimentally infected with $B$. melitensis $\mathrm{H} 38$ the antibody response to BP26 was delayed and much weaker than that to O-PS. Nevertheless, the BP26 protein appears to be a good diagnostic antigen to be used in confirmatory tests and for serological differentiation between infected and $B$. melitensis Rev.1-vaccinated sheep. Weak antibody responses to BP26 in some of the latter sheep suggest that a $B$. melitensis Rev.1 bp26 gene deletion mutant should be constructed to ensure this differentiation (Cloeckaert et al., 2001).

In a study by Kittelberger et al., (1998), a panel of 45 Brucella ovis serologically positive sera were tested in immunoblots against B. ovis outer membrane proteins Omp31 and Omp25, purified by preparative SDS-gel electrophoresis. Forty-three sera reacted with Omp31, while only 11 reacted with Omp25, suggesting that Omp31 is identical to the previously reported immunodominant 29-kDa protein. Attempts to purify Omp31 on a larger scale by using procedures such as ion exchange-, reversed phase-, affinity- and gel filtration chromatography suggested that the outer membrane proteins were aggregated with rough lipopolysaccharide. Only denaturing SDS-gel filtration chromatography was able to separate proteins of about $29 \mathrm{kDa}$ from rough lipopoly- saccharide but did not separate Omp31 from Omp25 in B. ovis preparations. Futher, sheep antibodies only reacted to LPS bound proteins and not purified proteins.

In a study by Al-Garadi (2011) CD markers and their combination in different populations of peripheral blood mononuclear cells (PMNC) were measured in detail, in different stages of $B$. melitensis infection and in experimentally infected mice and goats by using specific monoclonal antibody. The sensitivity of RBPT was $89.04 \%$ whilst that of CFT was $97.02 \%$. The specificity of RBPT and CFT was $99.06 \%$ and $96.38 \%$, respectively. Four B. melitensis isolates were obtained from 300 vaginal samples and all isolates belonged to $B$. melitensis biotype 1 . The real-time PCR was the easier and safer method for the confirmation of Brucellosis in goat populations. The $\mathrm{CD}$ biomarkers namely; CD14, CD4, CD25 markers were identified as good markers for the different stages of $B$. melitensis infection. A combination of a serological test namely RBPT and a molecular technique, in particular real-time PCR based on the IS711 region of a hypothetical protein, showed promising results. This combination can be used to reduce the number of false positive results, which can cause severe economical loss during the implementation of eradication programs.

In a study by Liu et al., (2012) 2Delectrophoresis and SDS-PAGE were applied to detect difference in plasma protein 
expression between healthy dairy cows and dairy cows suffering from Brucellosis. The results showed that 11 protein spots were found by PDQUest 8.0 Software and 5 of them were detected by ion trap mass spectrum. Apoprotein C-III and Serum Amyloid protein A (SAA) were acute phase protein and lipometabolism-related protein which can serve as the plasma biomarkers of Brucellosis for diagnosis.

Ahmed et al., (2015) conducted a study in which omp25, omp28 and omp31 of $B$. melitensis were cloned and expressed using prokaryotic pET-32 Ek/LIC system and their respective rOMPs were combined as one coating antigen to develop rOMPs I-ELISA. The production of rOMP25, rOMP28 and rOMP31 of B. melitensis were achieved and Western immunoblotting analysis demonstrated their reactivity. The RBPT was unable to differentiate the vaccinated mice (group 2) and mice infected with $Y$. enterocolitica $\mathrm{O}: 9$ (group 3) and categorized them wrongly as positive for Brucellosis. In contrast, the rOMPs I-ELISA was able to differentiate the mice infected with $B$. melitensis strain 0331 (group 1) from both group 2 and group 3, and recorded 100\% sensitivity and $100 \%$ specificity. The results of this study suggested that rOMPs of $B$. melitensis have potential diagnostic ability to differentiate the FPSR in serological diagnosis of Brucellosis.

Liang et al., (2010) conducted a study to better understand the antibody responses that develop after $B$. melitensis infection. A protein microarray was fabricated containing 1,406 predicted $B$. melitensis proteins. The array was probed with sera from experimentally infected goats and naturally infected humans from an endemic region in Peru. The assay identified 18 antigens differentially recognized by infected and noninfected goats, and 13 serodiagnostic antigens that differentiate human patients proven to have acute Brucellosis from syndromically similar patients. There were 31 cross-reactive antigens in healthy goats and 20 crossreactive antigens in healthy humans. Only two of the serodiagnostic antigens and eight of the cross-reactive antigens overlap between humans and goats. Based on these results, a nitrocellulose line blot containing the human serodiagnostic antigens was fabricated and applied in a simple assay that validated the accuracy of the protein microarray results in the diagnosis of human Brucellosis. These data demonstrate that an experimentally infected natural reservoir host produces a fundamentally different immune response than a naturally infected accidental human host.

Wareth et al., (2016) carried out a study to identify immunodominant proteins of two species of Brucella using antibodies present in the serum of naturally infected ruminants to gain insight on the mechanism of their infection in different hosts. In the study, whole-cell protein extracts of B. abortus and $B$. melitensis were separated using SDSPAGE and western blotting was performed using field sera from cows, buffaloes, sheep and goats. Protein bands that matched with western blot signals were excised, digested with trypsin and subjected to protein identification using MALDI-TOF MS. Identified proteins included heat shock proteins, enzymes, binding proteins and hypothetical proteins. Antibodies against the same set of antigens were found for all species investigated, except for superoxide dismutase of $B$. melitensis for which antibodies were demonstrated only in sheep serum. Brucellae appear to express these proteins mainly for their survival in the host system during infection.

Rolan et al., (2008) studied the vir B proteins were as potential biomarkers. The Brucella 
species type IV secretion system, encoded by the virB1-12 locus, is required for intracellular replication and persistent infection in vivo. VirB proteins are expressed in vivo and may therefore represent serological markers of infection. Purified recombinant VirB1, VirB5, VirB11, and VirB12 were tested for their recognition by antibodies in sera from experimentally infected mice and goats by using an indirect ELISA. Antibodies to VirB12 but not to VirB1, VirB5, or VirB11 were detected in 20/20 mice experimentally inoculated with Brucella abortus and 12/12 goats experimentally infected with Brucella melitensis. The potential use of VirB12 as a serological tool for the diagnosis of Brucellosis was evaluated in the natural bovine host. One hundred two out of 145 cattle samples $(70.3 \%)$ were positive for antibodies to VirB12, while 43 samples were negative $(29.7 \%)$. A positive serological response to VirB12 correlated with positive serology to whole B. abortus antigen in $99 \%$ of samples tested. They suggested that VirB12 may be a useful serodiagnostic marker for Brucellosis.

\section{References}

Adams L G and Schutta C. 2010. Natural resistance against Brucellosis: A review. The Open Veterinary Science Journal 4(1): 61-71.

Adel E G, Mohamed E B, Mahmoud A E H, Fatma E $G$ and Mona M E D. 2015. In vitro evaluation of commonly used disinfectants and antiseptics in Veterinary practice against Brucella abortus. Advances in Veterinary and Animal Sciences 2(4): 77-85.

Adosinda M C, Pinto M L, García Díez J and Coelho A C. 2015. Impact of B. melitensis Rev-1 vaccination on Brucellosis prevalence. Turkish Journal of Veterinary and Animal Sciences 39: 261-270.

Agasthya A S, Isloor S and Prabhudas K. 2007. Brucellosis in high risk group individuals. Indian Journal of Medical Microbiology 25: 28-31.

Ahmed I M, Khairani-Bejo S, Hassan L, Abdul Gani
B and Omar A R. 2015. Serological diagnostic potential of recombinant outer membrane proteins (rOMPs) from Brucella melitensis in mouse model using indirect enzyme-linked immunosorbent assay. BMC Veterinary Research 11:275.

Al Dahouk S, Tomaso H, Nöckler K, Neubauer H, Frangoulidis D. 2003. Laboratory-based diagnosis of brucellosis - a review of the literature. Part I: Techniques for direct detection and identification of Brucella spp. Clinical Laboratory 49(9-10): 487-505.

Al-Garadi M A M. 2011. Detection of infection and determination of biomarkers for Brucella melitensis infection in goats. $\mathrm{PhD}$ thesis, Universiti Putra Malaysia.

Alonso-Urmeneta B, Marin C M, Aragon V, Blasco J M, Diaz R and Moriyon I. 1998. Evaluation of lipopolysaccharides and polysaccharides of different epitopic structures in the enzymelinked immunosorbent assay for diagnosis of Brucellosis in small ruminants and cattle. Clinical Diagnostic and Laboratory Immunology 5: 749-754.

Alton G G and Forsyth J R L. 1996. Brucella. In Baron S, editor. Medical Microbiology. $4^{\text {th }}$ ed. Churchill Livingstone, New York.

Alton G G, Jones L M, Angus R D and Verger J M. 1988. Techniques for the Brucellosis Laboratory. INRA, Paris.

Alton G G. 1977. Report to the government of the United Arab Republic on the control of Brucellosis. FAO Report No. 1633, FAO, Rome.

Alton G G. 1990a. Brucella melitensis. In: Nielsen K and Duncan J R. (eds.) Animal Brucellosis. CRC Press Inc., Boca Raton, Florida pp 383409.

Alton G G. 1990b. Brucella suis. In: Nielsen K and Duncan J R. (eds.) Animal Brucellosis. CRC Press Inc., Boca Raton, Florida, 411-422.

Araj G F. 1989. Profiles of Brucella-specific immunoglobulin $G$ subclasses in sera of patients with acute and chronic Brucellosis. Serodiagnosis and Immunotherapy of Infectious Diseases 2: 401-410.

Ashraf M A, Ahmed K A, Torad F A and Marouf S A. 2015. Ultrasonographic and histopathological findings in rams with epididymo-orchitis caused by Brucella melitensis. Pakistan Veterinary Journal 35(4): 456-460.

Avinash Reddy D, Kumari G, Rajagunalan S, Singh 
D K, Kumar A and Pavan Kumar P. 2014. Seroprevalence of caprine brucellosis in Karnataka. Veterinary World 7(3): 182-188.

Baldwin C L and Goenka R. 2006. Host immune responses to the intracellular bacteria Brucella: Does the bacteria instruct the host to facilitate chronic infection? Critical Reviews in Immunology 26: 407-442.

Banai M. 2007. Control of Brucella melitensis. Memorias del IV Foro Nacional de Brucelosis, Facultad de Medicina Veterinaria y Zootecnia de la Universidad Nacional Autónoma de México (FMVZ-UNAM), 26-27 November, Mexico, DF.

Barroso G P, Pelayo R C and Extremera G. 2002. Study of 1595 brucellosis cases in the Almeria province (1972-1998) based on epidemiological data from disease reporting. Review de Clinics de Espana 202: 577-82.

Behroozikhah A M, Nejad R B, Amiri $\mathrm{K}$ and Bahonar A R. 2012. Identification at Biovar level of Brucella isolates causing abortion in small ruminants of Iran. Journal of Pathogens ID 357235, 1-4.

Bellaire B H, Roop $2^{\text {nd }} \mathrm{R}$ M and Cardelli J A. 2005. Opsonized virulent Brucella abortus replicates within nonacidic, endoplasmic reticulumnegative, LAMP-1-positive phagosomes in human monocytes. Infection and Immunity 73: 3702-3713.

Bhonghibhat N, Elberg S, Chen H T. 1970. Characterization of Brucella skin test antigens. Journal of Infectious Diseases 122: 70-82.

Biancifiori F, Garrido F, Nielsen K, Moscati L, Durán M and Gall D. 2000. Assessment of a monoclonal antibody based competitive enzyme linked immunosorbent assay (cELISA) for diagnosis of Brucellosis in infected and Rev. 1 vaccinated sheep and goats. New Microbiology 23(4): 399-406.

Blasco J M and Molina-Flores B. 2011. Control and eradication of Brucella melitensis infection in sheep and goats. Veterinary Clinics of North America (Food Animal Practice) 27 (1): 95104.

Blasco J M, Garin-Bastuji B, Marın C M, Gerbier G, Fanlo J, Jimenez de Bagues M P and Cau C. 1994a. Efficacy of different Rose Bengal and complement fixation antigens for the diagnosis of Brucella melitensis in sheep and goats. Veterinary Record 134: 415-420.

Blasco J M, Marın C, Jimenez de Bagues M P, Barberan M, Hernandez A, Molina L, Velasco
J, Diaz R and Moriyon I. 1994b. Evaluation of allergic and serological tests for diagnosing Brucella melitensis infection in sheep. Journal of Clinical Microbiology 32:1835-1840.

Blasco J M. 1997. A review of the use of $B$. melitensis Rev 1 vaccine in adult sheep and goats. Preventive Veterinary Medicine 31(3-4): 275-83.

Bricker B J, Ewalt D R and Halling S M. 2003. Brucella 'HOOFPrints': strain typing by multilocus analysis of variable number tandem repeats (VNTRs). BMC Microbiology 3: 1527.

Capasso L. 2002. Bacteria in two millennia - old cheese, and related epizoonosis in Roman populations. Journal of Infection 45: 122-127.

Celli J and Gorvel J P. 2004. Organelle robbery: Brucella interactions with the endoplasmic reticulum. Current Opinion in Microbiology 7 (1): 93-97.

Centers for Disease Control and Prevention [CDC]. 2005. Brucellosis (Brucella melitensis, abortus, suis, and canis). http://www.cdc.gov/ncidod/dbmd/diseaseinfo/ Brucellosis_t.ht m.**.

Cerri D, Ambrogi C, Ebani V V, Poli A, Cappelli F, Cardini G and Andreani E. 2002. Experimental Brucella ovis infection in mouflon (Ovis musimon). Journal of Wildlife Diseases 38: 287-90.

Chand P, Sadana J R and Malhotra A K. 2002. Epididymoorchitis caused by Brucella melitensis in breeding rams in India. Veterinary Record 150 (3): 84-85.

Cloeckaert A, Debbarh H S A, Vizca'ino N, Saman E, Dubray G and Zygmunt M S. 1996a. Cloning, nucleotide sequence, and expression of the Brucella melitensis bp26 gene coding for a protein immunogenic in infected sheep. FEMS Microbiology Letters 140: 139-144.

Cloeckaert A, Debbarh H S A, Zygmunt M S and Dubray G. 1996b. Production and characterization of monoclonal antibodies to Brucella melitensis cytosoluble proteins that are able to differentiate antibody responses of infected sheep from Rev 1 vaccinated sheep. Journal of Medical Microbiology 45: 206-213.

Cloeckaert A, Grayon M and Grepinet O. 2002. Identification of Brucella melitensis vaccine strain Rev.1 b PCR-RFLP based on a mutation in the rpsL gene. Vaccine 20: 2546-2550.

Corbel M J and Brinley - Morgan W J. 1984. Genus Brucella, In: Krieg N R, Holt J G, editors. 
Bergey's Manual of Systematic Bacteriology. Vol. 1. The Williams and Wilkins Co. Baltimore pp. 377-388.

Corbel M J. 1985. Recent advances in the study of Brucella antigens and their serological crossreactions. Veterinary Bulletin 55: 927-942.

Corbel M J. 1997. Brucellosis: an overview. Emerging Infectious Diseases 3(2): 213-221.

Cutler S J, Whatmore A M and Commander N J. 2005. Brucellosis - new aspects of an old disease. Journal of Applied Microbiology 98: 1270 - 1281.

Debbarh H S A, Cloeckaert A, B'ezard G, Dubray G. and Zygmunt M S. 1996a. Enzyme-linked immunosorbent assay with partially purified cytosoluble 28-kilodalton protein for serological differentiation between Brucella melitensis infected and Brucella melitensis Rev 1 vaccinated sheep. Clinical Diagnostic and Laboratory Immunology 3: 303 - 308.

Debbarh H S A, Cloeckaert A, Zygmunt M S. and Dubray G. 1995. Identification of seroreactive Brucella melitensis cytosoluble proteins which discriminate between antibodies elicited by infection and Rev 1 vaccination in sheep. Veterinary Microbiology 44: 37-48.

Debbarh H S A, Zygmunt M, Dubray G. and Cloeckaert A. 1996b. Competitive enzymelinked immunosorbent assay using monoclonal antibodies to the $B$. melitensis $\mathrm{BP} 26$ protein to evaluate antibody responses in infected and $B$. melitensis Rev 1 vaccinated sheep. Veterinary Microbiology 53: 325-337.

Delgado S, Fernandez M. and Carmenes P. 1995. Evaluation of an enzyme-linked immunosorbent assay for the detection of sheep infected and vaccinated with Brucella melitensis. Journal of Veterinary Diagnostic Investigation 7: 206-209.

Dénes B and R Glávits. 1994. Bacteriologically confirmed cases of ovine epididymo-orchitis caused by Brucella ovis in Sub-Carpathia. Acta Veterinaria Hungarica 42: 25-33.

Desai T, Krishnappa G and Upadhyaye A S. 1995. Incidence of brucellosis in sheep, goats and some human risk groups. Mysore Journal of Agricultural Science 29: 348-351.

Díaz R and Bosseray N. 1974. Influence de 1' Infection Par Brucella abortus sur 1' hypersensibilite et l' hyperreactivite de la souris aux endotoxines de Brucella melitensis, Yersinia enterocolotica et E. coli. Annales de Recherche de Veterinaires 5: 41-56.
Díaz R, Jones L M and Wilson J B. 1967. Antigenic relationship of Brucella ovis and Brucella melitensis. Journal of Bacteriology 93: 1262.

Díaz R, Jones L M. and Wilson J B. 1968. Antigenic relationship of the Gram-negative organism causing canine abortion to smooth and rough Brucellae. Journal of Bacteriology 95: 618.

Díaz-Aparicio E, Aragón V, Marín C, Alonso B, Font M, Moreno E, Pérez-Ortiz S, Blasco J M, Díaz R and Moriyón I.1993. Comparative analysis of Brucella serotype A and $\mathrm{M}$ and Yersinia enterocolitica O:9 polysaccharides for serological diagnosis of brucellosis in cattle, sheep, and goats. Journal of Clinical Microbiology 31(12): 3136-3141.

European Commision. 2001. Brucellosis in sheep and goats. Report of the Scientific Committee on Animal Health and Animal Welfare, EC. 2:10-16.

Falade S. 1978. A comparison of three serological tests in the diagnosis of caprine brucellosis. Research in Veterinary Science 24(3): 376-377.

Farina R, 1985. Current serological methods in Brucella melitensis diagnosis. Brucella melitensis. CEC seminar, Brussels, November 1984. 139-146. Current Topics in Veterinary Medicine and Animal Science 32.

Farrell I D. 1974. The development of a new selective medium for the isolation of Brucella abortus from contaminated sources. Research in Veterinary Science 16(3): 280-286.

Fekete A, Bantle J A, Halling S M and Stich R W. 1992. Amplification fragment length polymorphism in Brucella strains by use of polymerase chain reaction with arbitrary primers. Journal of Bacteriology 174: 77787783.

Fensterbank R and Maquere M. 1978. Assainissement d'un troupeauovin atteint de brucellose par les moyens de la prophylaxie sani-taire en utilisant l'epreuve au Rose Bengale. Recherche de Medicines Veterinaire 154: 657-661.

Fensterbank R, Pardon P and Marly J. 1982. Comparison between subcutaneous and conjunctival route of vaccination with Rev. 1 strain against Brucella melitensis infection in ewes. Annales de Recherche de Veterinaires. 13(4): 295-301.

Fensterbank R. 1985. Allergic diagnosis of Brucellosis. In: Verger J M. and Plommet M. (Eds.), Brucella melitensis. Martinus Nijhoff. pp. 167-172. 
Ferreira A C, Cardoso R, Travassos Dias I, Mariano I, Belo A, Rolao Preto I, Manteigas A, Pina Fonseca A M. and Correa De Sa M I. 2003. Evaluation of a modified Rose Bengal test and an indirect enzyme-linked immunosorbent assay for the diagnosis of Brucella melitensis infection in sheep. Veterinary Research 34: 297-305.

Ficapal A, Alonso B, Velasco J, Moriyon I. and Blasco J M. 1995. Diagnosis of B. ovis infection of rams with an ELISA using protein $\mathrm{G}$ as conjugate. Veterinary Record 137: 145147.

Franco M P, Mulder M, Gilman R H and Smits H L. 2007. Human Brucellosis. The Lancet Infectious Diseaes 7(12): 775-786.

Garin-Bastuji B, Blasco J M, Grayon M, Verger J M. 1998. Brucella melitensis infection in sheep: present and future. Veterinary Research 29(3/4): 255-274.

Garin-Bastuji B. and Blasco J M. 2004. Caprine and ovine Brucellosis (excluding B. ovis). In: Manual of Diagnostic Tests and Vaccines for Terrestrial Animals, $5^{\text {th }}$ ed. OIE, pp. 598-606.

Garner G, Saville P and Fediaevsky A. 2003. Caprine and ovine Brucellosis (excluding $B$. ovis). In Manual for the Recognition of Exotic Diseases of Livestock: A Reference Guide for Animal Health Staff. Food and Agriculture Organization of the United Nations [FAO]: B152.

Geering W A, Forman J A, and Nunn M J. 1995. Exotic Diseases of Animals. Aust. Gov. Publishing Service, Canberra, Australia, pp 301-306.

Gill, J P S, Kaur S, Joshi D V, and Sharma J K. 2000. Proceedings of the 9th International Symposium on Veterinary Epidemiology and Economics, Punjab Agricultural University, Ludhiana. Ludhiana.

Godfroid J, Scholz H C, Barbier T, Nicolas C, Wattiau P, Fretin D, Whatmore A M, Cloeckaert A, Blasco J M, Moriyon I, Saegerman C, Muma J B, Al Dahouk S, Neubauer H. and Letesson J. 2011. Brucellosis at the animal / ecosystem / human interface at the beginning of the 21st century. Preventive Veterinary Medicine 102: 118-131.

Goldbaum F A, Leoni J, Wallach J C and Fossati C A. 1993. Characterization of an 18-kilodalton Brucella cytoplasmic protein which appears to be a serological marker of active infection of both human and bovine brucellosis. Journal of
Clinical Microbiology 31(8): 2141-2145.

Grewal, S.S. and Kaur, S. 2000. Survey of sheep and goat brucellosis in Sangrur district (Punjab, India). Journal of Parasitology and Applied Animal Biology 9: 67-74.

Grillo M.J., Barberán M. \& Blasco J.M. 1997. Transmission of Brucella melitensis from sheep to lambs. Veterinary Record 140 (23): 602-605.

Hemmen F, Weynants V, Scarcez T, Letesson J J and Saman E. 1995. Cloning and sequence analysis of a newly identified Brucella abortus gene and serological evaluation of the 17kilodalton antigen that it encodes. Clinical Diagnostic and Laboratory Immunology 2(3): 263-267.

Herrera E, Rivera A, Palomares E G, HernándezCastro R. and Díaz-Aparicio E. 2011. Isolation of Brucella melitensis from a RB51-vaccinated seronegative goat. Tropical Animal Health and Production 46 (6): 1069-1070.

Hinić V, Brodard I, Petridou E, Filioussis G, Contos V, Frey J. and Abril C. 2012. Brucellosis in a dog caused by Brucella melitensis Rev 1 . Veterinary Microbiology 141 (3-4): 391-392.

http://europa.eu.int/comm/food/fs/sc/scah/out59_en. pdf.

Isloor S, Renukaradhya $\mathrm{G} \mathrm{J}$ and Rajashekhar $\mathrm{M}$. 1998. Brucellosis research. In Annual Report (1997-1998) of AICRP on Animal Disease Monitoring and Surveillance. Bangalore, India pp 13-18.

Jiménez de Bagüés M P, Marin C M and Blasco J M. 1992. An ELISA with Brucella lipopolysaccharide antigen for the diagnosis of $B$. melitensis infection in sheep and for the evaluation of serological responses following subcutaneous or conjunctival B. melitensis strain rev. 1 vaccination. Veterinary Microbiology 30: 233-241.

Jones L M and Marly J. 1975. Titration of a Brucella protein allergen in sheep sensitized with Brucella melitensis. Annales des Recherches des Veterinaires 6(2): 173-8.

Jones L M, Díaz R, Taylor A G. 1973. Characterizations of allergens prepared from smooth and rough strains of Brucella melintensis. British Journal of Experimental Pathology 54: 492-508.

Jones L M. 1974. Specificity of Brucella protein antigens and role of lipopolysacharide antigens in eliciting delayed hypersensitivity reactions in sensitized guinea pigs. Annales des Recherches 
Veterinaire 5: 189-199.

Kahn C M and Line S. 2003. Brucellosis in goats. The Merck Veterinary Manual [online]. Whitehouse Station, NJ: Merck and Co; http://www.merckvetmanual.com/mvm/index.j $\mathrm{sp}$ ?cfile $=\mathrm{htm} / \mathrm{b} \mathrm{c} / 110503 . \mathrm{htm}$.

Kapur M P and Grewal J S. 1974. Prevalence of Brucellosis in domestic animals in Haryana state. Haryana Veterinarian 13: 1-4.

Katoch R C, Joshi V B, Sharma M, Batta M K and Nagal K B. 1996. Seroprevalence of Brucella ovis, Brucella melintensis and Chlamydia psittaci in rams. Indian Journal of Animal Sciences 66(11): 1130-1131.

Kittelberger R and Reichel M P. 1998. Evaluation of electrophoretic immunoblotting for Brucella ovis infection in deer using ram and deer serum. New Zealand Veterinary Journal 46: 32-34.

Kotadiya A J, Kumar P, Patel K M, Patel M V, Shroff S I, Dadawala A I, Shrimali M D, Bhagat A, Chandel B S, and Shah N M. 2015. Seroprevalence of ovine Brucellosis in North Gujarat and Kutchh Regions of Gujarat by iELISA and its Comparison with RBPT and STAT. Indian Veterinary Journal 92 (11) : 42 $-46$.

Kumar P K, Singh D K and Barbuddhe S B. 1997. Serological evidence of brucellosis in sheep and goats. Indian Journal of Animal Sciences 67(3): 180-182.

Liang Li, Leng D, Burk C, Nakajima-Sasaki R, Kayala A, Matthew L, Vidya A, Jozelyn P, Berkay U, A. Thomas F, Eduardo G, Mayuko S, Morrow W, John W, Xiaowu L, Pierre B, Gilman Robert H, M. Vinetz Joseph Tsolis Renée M. and Felgner Philip L. 2010. Large scale immune profiling of infected humans and goats reveals differential recognition of Brucella melitensis antigens. PLoS Neglected Tropical Diseases 4(5): e673. doi: 10.1371/journal.pntd.0000673

Lim M L and Rickman L S. 2004. Brucellosis. Journal of Infectious Diseases in Clinical Practice Volume 12(1): 7-14.

Liu S, Tao J, Guo Y, Feng L, Zhao G, Wu Q, Yang X, Kuai S, and Wang J. 2012. Comparative proteomic studies on serum of Brucellosis affected dairy cows and healthy dairy cows. Journal of Animal and Veterinary Advances 11: 1864-1867.

Lone I M, Baba M A, Shah M M, Iqbal A and Sakina A. 2013. Seroprevalence of brucellosis in sheep of organized and unorganized sector of Kashmir valley. Veterinary World 6(8): 530533.

Mackaness G B. 1964. The immunological basis of acquired cellular resistance. Journal of Experimental Medicine 120: 105-120.

MacMillan A. 1990. Conventional serological tests. In Nielsen K and Duncan J R. (Eds.), Animal Brucellosis, CRC Press, Boca Raton, Florida pp. 153-197.

Manat Y, Shustov A V, Evtehova E, and Eskendirova S Z. 2016. Expression, purification and immunochemical characterization of recombinant OMP28 protein of Brucella species. Open Veterinary Journal 6(2): 71-77.

Mantur B G, Amarnath S K and Shinde R S. 2007. Review of clinical and laboratory features of human Brucellosis. Indian Journal of Medical Microbiology 25: 188-202.

Moreno E, Cloeckaert A, Moriyón I. 2002. Brucella evolution and taxonomy. Veterinary Microbiology 90: 209-227.

Morgan, W J B. 1982. Brucella Abortus (review) In handbuch der bacteriellen Infection en bei teiren, Vol 4, Blobel, $\mathrm{H}$ and Schleisser T. eds, Fischer, Frankfurt am main, 53.

Mrunalini N, Shastry R, Pandarinath G N and Ramakrishna Rao M. 2000. Sero-incidence of brucellosis among dairy farm workers in Orissa. Indian Veterinary Journal 77: 568-570.

Mythili T, Rajendra L, Bhavesh T, Thiagarajan D and Srinivasan V A. 2011. Development and comparative evaluation of a competitive ELISA with Rose Bengal Test and a commercial indirect ELISA for serological diagnosis of Brucellosis. Indian Journal of Microbiology 51: 528 .

Nicoletti P. 1989. Relationship between animal and human disease. In Brucellosis: Clinical and laboratory aspects CRC Florida, pp 41-51.

Nicoletti P. 2013. Brucellosis in cattle. In Merck Veterinary Manual. www.merckvetmanual.com

Nielsen K H, Kelly L, Gall D, Balsevicus S, Bosse J, Nicolitti P and Kelly W. 1996. Comparison of enzyme immunoassays for the diagnosis of bovine Brucellosis. Preventive Veterinary Medicine 26: 17-32.

Nielsen K. and Gall D. 2001. Fluorescence polarization assay for the diagnosis of Brucellosis: a review. Journal of Immunoassay and Immunochemistry 23: 183-201.

Ogredici O, Erb S, Langer I et al., 2010. Brucellosis 
reactivation after 28 years. Emerging Infectious Diseases 16: 2021-2022.

OIE. 2008. Bovine brucellosis. In Manual of diagnostic tests and vaccines. OIE, Paris, pp.624- 659.

OIE. 2009. Bovine Brucellosis, Section 2.4.3. Manual of the Diagnostic Tests and Vaccines for Terrestrial Animals, vol. 1., $5^{\text {th }}$ edition Office International Des Epizooties, Paris, France, pp 1-35.

Oliveira S C and Splitter G A.1994. Subcloning and expression of Brucella abortus L7/L12 ribosomal gene and $\mathrm{T}$ lymphocyte recognition of the recombinant protein. Infection and Immunity 62: 5201-5204.

Oomen L J and Waghela S. 1974. The Rose Bengal Plate Test in human brucellosis. Tropical and Geographical Medicine 26 (3): 300-02.

Pappas G, Akritidis N, Bosilkovski M. and Tsianos E. 2005. Brucellosis. New England Journal of Medicine 352: 2325-2336.

Pardon P, Sanchis R, Molenat G, Bouchard N, Schmitt D, Marly J. and Durand M. 1989. Persistence of serologic and allergic reactions in ewes after vaccination with the H.38 or Rev. 1 vaccines in a brucellosis (Brucella melitensis) enzootic area. Annales des Recherche des Veterinaires 20: 65-72.

Poester F P, Samartino L E and Santos R L. 2013. Pathogenesis and pathobiology of brucellosis in livestock. Reviews in Science and Technology Office Internationale des Epizootes 32(1): 105115.

Priya P M, Baburaj N K, Kiran N and Rajan S. 2010. Brucellosis in Wayanad tribal goat population: A preliminary serological survey. Journal of Advanced Laboratory Research in Biology Volume I, Issue II.

Radunz B L. and Lepper W. 1985. Suppression of skin reactivity to bovine tuberculin in repeated tests. Australian Veterinary Journal 62: 191196.

Refai M. 2002. Incidence and control of brucellosis in the Near East region. Veterinary Microbiology 90: 81-110.

Ridler A L, West D M, Stafford K J, Wilson P R and Collett M G. 2002. Effects of vaginal Brucella ovis infection of red deer hinds on reproductive performance, and venereal transmission to stags. New Zealand Veterinary Journal 50: 126-131.

Rolán H G, Den Hartigh A B, Kahl-McDonagh M, Ficht T, Adams L G and Tsolis R M. 2008.
VirB12 is a serological marker of Brucella infection in experimental and natural hosts. Clinical and Vaccine Immunology 15(2): 20814.

Romero C and Lopez-Goñi I. 1999. Improved method for purification of bacterial DNA from bovine milk for detection of Brucella spp. by PCR. Applied Environmental Microbiology 65(8): 3735-3737.

Rossetti O L, Arese A I, Boschiroli M L and Cravero S L. 1996. Cloning of Brucella abortus gene and characterization of expressed 26-kilodalton periplasmic protein: potential use for diagnosis. Journal of Clinical Microbiology 34: 165-169.

Ruiz-Mesa J D, Gonzalez J S, Reguera J M, Martin L, Palmero S L and Colmenero J D. 2005. Rose Bengal Test: diagnostic yield and use for the rapid diagnosis of human brucellosis in emergency departments in endemic areas. Clinical Microbiology and Infection. 11(3): 221-225.

Sadhu D B, Panchasara H H, Chauhan H C, Sutariya D R, Parmar V L, and Prajapati H B. 2015. Seroprevalence and comparison of different serological tests for brucellosis detection in small ruminants. Veterinary World 8(5): 561-566.

Saravi M, Gregoret R J, Wright P F and Gall D. 1990. Comparison of an indirect enzyme immunoassay and conventional serological techniques for the detection of bovine antibody for Brucella abortus. Proceedings of Final Research Coordination Meeting of FAO/IAEA/SIDA, Austria. pp. 151-162.

Sauret J M and Vilissova N. 2002. Human Brucellosis. Journal of American Board of Farm Practice 15: 401-406.

Seleem M N, Boyle S M, Sriranganathan N. 2010. Brucellosis: A re-emerging zoonosis, Veterinary Microbiology 140: 392-398.

Singh S V, Aggarwal G S, Batra H V, Gupta V K and Singh N. 2000. Monitoring of Brucella infection associated with reproductive losses using multiple serological tests in organized goat and sheep flocks. Indian Journal of Animal Science 70(2): 154-156.

Skendros $P$ and Boura P. 2013. Immunity to brucellosis. Reviews in Science and Technology 32(1): 137-47.

Smits H L and Kadri S M. 2005. Brucellosis in India: a deceptive infectious disease. Indian Journal of Medical Research 122: 375-84. 
Suryawanshi S N, Tembhurne P A, Gohain S and Ingle V C. 2014. Prevalence of Brucella antibodies in sheep and goats in Maharashtra. Indian Research Journal of Extension Education 14(4) (Special Issue): 75-77.

Sutherland S S, Evans R J and Bathgate J. 1986. Application of an enzyme linked immunosorbent assay in the final stages of a bovine Brucellosis eradication program. Australian Veterinary Journal 63: 412-415.

Tibary A, Fite C, Anouassi A, Sghiri A. 2006. Infectious causes of reproductive loss in camelids. Theriogenology 66: 633- 647.

U.S. Department of Agriculture, Animal and Plant Health Inspection Service [USDA-APHIS]. 1999. Center for Emerging Issues [CEI]. Brucella melitensis in Texas, October Impact worksheet [online]. USDA APHIS, CEI; 1999. http://www.aphis.usda.gov/vs/ceah/cei/taf/iw_1 999 file/brucellatexas 1099.htm*

Vemulapalli T H. 2000. Genetic and immunological analyses of a Brucella abortus protein exhibiting lectin-like properties. Thesis. Virginia Polytechnic Institute and State University, USA.

Verger J M, Garin-Bastuji B, Grayon M. and Mahé A M. 1989. Bovine Brucellosis caused by Brucella melitensis in France. Annals of Veterinary Research 20(1): 93-102.

Wareth G, Melzer F, Weise C, Neubauer H, Roesler U, and Murugaiyan J. 2016. Proteomics-based identification of immunodominant proteins of Brucellae using sera from infected hosts points towards enhanced pathogen survival during the infection.http://www.sciencedirect.com/science /article/pii/S0006291X14020890>.

Webb R F, Quinn C A, Cockram F A and Husband A J. 1980. Evaluation of procedures for the diagnosis of Brucella ovis infection in rams.
Australian Veterinary Journal 56: 172-175.

Winter A J. 1987. Outer membrane proteins of Brucella. Annals of Institut Pasteur Microbiology 138: 87.

Xavier M N, Paixao T A, Poester F P, Lage A P and Santos R L. 2009. Pathological, immunohistochemical and bacteriological study of tissues and milk of cows and fetuses experimentally infected with Brucella abortus. Journal of Comparative Pathology 140 (2-3): 149-157.

Yantorno O Y, Mazza L A, Balatti A P and Aguirre W. 1978. Influence of the sterilization technic and culture media components on the growth and dissociation of Brucella abortus strain 19 in submerged cultures. Revista de la Asociacion Argentina de Microbiologia 10(3): 83-93.

Yilma M, Mamo G, Mammo B. 2016. Review on brucellosis sero-prevalence and ecology in livestock and human population. Achievements in the Life Sciences 10(1): $80-86$.

Yongqun H E. 2012. Analyses of Brucella pathogenesis, host immunity, and vaccine targets using systems biology and bioinformatics. Frontiers in Cellular and Infection Microbiology Issue 2: 2.

Zygmunt M S, Cloeckaert A and Dubray G. 1994a. Brucella melitensis cell envelope protein and lipopolysaccharide epitopes involved in humoral immune responses of naturally and experimentally infected sheep. Journal of Clinical Microbiology 32(10): 2514-2522.

Zygmunt M S, Debbarh H S A, Cloeckaert A and Dubray G. 1994b. Antibody response to Brucella melitensis outer membrane antigens in naturally infected and Rev 1 vaccinated sheep. Veterinary Microbiology 39: 33-46.

\section{How to cite this article:}

Neharika Saxena, Balbir Bagicha Singh and Hari Mohan Saxena. 2018. Brucellosis in Sheep and Goats and Its Serodiagnosis and Epidemiology. Int.J.Curr.Microbiol.App.Sci. 7(01): 18481877. doi: https://doi.org/10.20546/ijcmas.2018.701.225 